\title{
Targeting the myeloid checkpoint receptor SIRPa potentiates innate and adaptive immune responses to promote anti-tumor activity
}

\author{
Tracy C. Kuo 1,3*0 , Amy Chen 1,3, Ons Harrabi 1,3, Jonathan T. Sockolosky 1,4, Anli Zhang², Emma Sangalang 1,3, \\ Laura V. Doyle ${ }^{1,3}$, Steven E. Kauder ${ }^{1,5}$, Danielle Fontaine ${ }^{1,3}$, Sangeetha Bollini ${ }^{1}$, Bora Han ${ }^{1,6}$, Yang-Xin Fu ${ }^{2}$, \\ Janet $\operatorname{Sim}^{1,3}$, Jaume Pons ${ }^{1}$ and Hong I. Wan ${ }^{1,3}$
}

\begin{abstract}
Background: Signal regulatory protein a (SIRPa) is a myeloid-lineage inhibitory receptor that restricts innate immunity through engagement of its cell surface ligand CD47. Blockade of the CD47-SIRPa interaction synergizes with tumor-specific antibodies and T-cell checkpoint inhibitors by promoting myeloid-mediated antitumor functions leading to the induction of adaptive immunity. Inhibition of the CD47-SIRPa interaction has focused predominantly on targeting CD47, which is expressed ubiquitously and contributes to the accelerated blood clearance of anti-CD47 therapeutics. Targeting SIRPa, which is myeloid-restricted, may provide a differential pharmacokinetic, safety, and efficacy profile; however, SIRPa polymorphisms and lack of pan-allelic and species cross-reactive agents have limited the clinical translation of antibodies against SIRPa. Here, we report the development of humanized AB21 (hAB21), a pan-allelic anti-SIRPa antibody that binds human, cynomolgus monkey, and mouse SIRPa alleles with high affinity and blocks the interaction with CD47.
\end{abstract}

Methods: Human macrophages derived from donors with various SIRPa v1 and v2 allelic status were used to assess the ability of hAB21 to enhance phagocytosis. HAB21_lgG subclasses were evaluated for targeted depletion of peripheral blood mononuclear cells, phagocytosis and in vivo efficacy in xenograft models. Combination therapy with anti-PD1/anti-PD-L1 in several syngeneic models was performed. Immunophenotyping of tissues from MC38 tumor-bearing mice treated with AB21 and anti-PD-1 was evaluated. PK, PD and tolerability of hAB21 were evaluated in cynomolgus monkeys.

Results: SIRPa blockade with hAB21 promoted macrophage-mediated antibody-dependent phagocytosis of tumor cells in vitro and improved responses to rituximab in the Raji human tumor xenograft mouse model. Combined with PD-1/PD-L1 blockade, AB21 improved response rates by facilitating monocyte activation, dendritic cell activation, and T cell effector functions resulting in long term, durable antitumor immunity. In cynomolgus monkeys, hAB21 has a half-life of 5.3 days at $10 \mathrm{mg} / \mathrm{kg}$ and complete target occupancy with no hematological toxicity or adverse findings at doses up to $30 \mathrm{mg} / \mathrm{kg}$.

Conclusions: The in vitro and in vivo antitumor activity of hAB21 broadly recapitulates that of CD47 targeted therapies despite differences in ligand expression, binding partners, and function, validating the CD47-SIRPa axis as a

\footnotetext{
*Correspondence: tracy@tallactx.com

${ }^{1}$ ALX Oncology, Burlingame, CA, USA

Full list of author information is available at the end of the article
} permits use, sharing, adaptation, distribution and reproduction in any medium or format, as long as you give appropriate credit to the original author(s) and the source, provide a link to the Creative Commons licence, and indicate if changes were made. The images or other third party material in this article are included in the article's Creative Commons licence, unless indicated otherwise in a credit line to the material. If material is not included in the article's Creative Commons licence and your intended use is not permitted by statutory regulation or exceeds the permitted use, you will need to obtain permission directly from the copyright holder. To view a copy of this licence, visit http://creativecommons.org/licenses/by/4.0/. The Creative Commons Public Domain Dedication waiver (http://creativeco mmons.org/publicdomain/zero/1.0/) applies to the data made available in this article, unless otherwise stated in a credit line to the data. 
fundamental myeloid checkpoint pathway and its blockade as promising therapeutic intervention for treatment of human malignancies.

Keywords: SIRPa, CD47, Macrophage, Phagocytosis, Immunotherapy, Innate immune checkpoint, Adaptive immunity

\section{Background}

The clinical development of immune checkpoint inhibitors (ICIs) has dramatically changed the landscape of cancer treatment [1-3]. ICIs targeting T-cell inhibitory receptors can induce complete and durable tumor immunity in patients with metastatic and treatment-refractory cancers. Despite the clinical promise of ICIs, only a fraction of patients within the ICI responsive cancer subtypes benefit from treatment with antibodies against PD-1, PD-L1, and CTLA4. Cancer is highly heterogeneous and complex and exploits a variety of mechanisms to evade immune surveillance beyond suppression of antitumor $\mathrm{T}$ cell responses [4]. Tumor-associated macrophages constitute a large fraction of the immune cell infiltrates within the tumor microenvironment of many human cancers [5]. Dendritic cells (DCs), although low in frequency within tumors, are potent and crucial mediators of antitumor immunity [6]. Given their prevalence and immunomodulatory activities, targeting regulators of macrophage and DC function is an attractive strategy to augment antitumor immunity and achieve additive or synergistic efficacy in combination with antitumor antibodies or ICIs.

Signal regulatory protein $\alpha(\operatorname{SIRP} \alpha)$ is an immunoinhibitory receptor expressed primarily by cells of the myeloid lineage including monocytes, macrophages, DCs, and neutrophils [7]. Upon interaction with its principal ligand, CD47, SIRP $\alpha$ transmits inhibitory signals that regulate DC homeostasis, self-recognition, and macrophage-mediated programmed cell removal [7, 8]. During malignant transformation, many human tumors exploit upregulation of CD47 thus activation of SIRP $\alpha$ signaling to avoid phagocytic clearance, resulting in the suppression of myeloid-mediated innate immunity and poor induction of antigen-specific immunity. SIRP $\alpha$ negatively regulates DC maturation, antigen presentation [9], and proinflammatory cytokine secretion [10]. In addition, it counteracts activating signals mediated by antibody engagement of $\mathrm{Fc} \gamma$ receptors $(\mathrm{Fc} \gamma \mathrm{R})$, which profoundly limits antibody-dependent cellular phagocytosis (ADCP) against tumors, restricts neutrophil transmigration [11], and maintains myeloid-derived suppressor cell (MDSC) functions [12]. Given the broad negative regulatory roles of SIRP $\alpha$ on innate immunity, a variety of CD47-SIRP $\alpha$ antagonists have been developed to promote the antitumor activity of phagocytes and myeloid cells. Blockade of the CD47-SIRPa interaction synergizes with both tumor-specific antibodies and ICIs by effectively reprogramming the myeloid compartment toward a proinflammatory phenotype improving tumor cell phagocytosis, antigen presentation, and $\mathrm{T}$ cell priming $[9,13]$. A number of CD47 antagonists have entered the clinic with promising anticancer activity in both hematological and solid tumors [14-18].

Efforts to disrupt the CD47-SIRP $\alpha$ interaction have mainly focused on targeting CD47 due to its upregulation and ubiquitous expression on most human tumor types. However, CD47 is also broadly expressed on virtually all normal cells, including red blood cells and platelets, which creates a large antigen sink and CD47 blockers comprising an active Fc have shown dose-dependent cytopenia $[19,20]$. We have previously shown that safety liabilities associated with CD47 blockers with active Fc domains can be overcome by eliminating Fc effector function [13, 16, 17, 21]. Targeting SIRPa is an orthogonal approach to inhibit the CD47-SIRP $\alpha$ pathway.

Herein, we explore pre-clinical pharmacology, pharmacokinetics, and exploratory safety associated with antibody-based blocking and antagonism of SIRP $\alpha$. Utilizing an anti-SIRP $\alpha$ antibody we discovered in human antibody transgenic chickens [22], we demonstrate that pan-allelic anti-SIRP $\alpha$ antibody hAB21, which blocks the CD47-SIRP $\alpha$ interaction, broadly recapitulates the functional properties of CD47 antagonists by promoting the anticancer activity of both tumor-specific antibodies and ICIs in a macrophage and DC dependent manner. This leads to the induction of adaptive immunity, resulting in complete and durable antitumor responses in mice. HAB21 exhibits favorable safety and pharmacokinetic (PK) profiles in monkeys with no hematological or immune-related adverse events. Thus, targeting SIRP $\alpha$ with hAB21 is a promising therapeutic approach to treat human cancers by reprogramming innate immunity to sensitize cancers to immunotherapy.

\section{Methods \\ Expression and purification}

All antibodies were expressed in Expi293 cells (Invitrogen) using standard manufacturer's protocol. Expression cultures were typically grown for 5 days at $37{ }^{\circ} \mathrm{C}$ in $8 \% \mathrm{CO}_{2}$. Supernatants were harvested via centrifugation and sterile filtered. Proteins were affinity purified 
utilizing MabSelect Sure LX resin (GE Healthcare). For SPR screening, the IgV domains of human SIRPa v1 (NP_542970.1) and human SIRP $\alpha$ v2 (CAA71403.1) are expressed in Expi293 cells as described above as either a His-tagged or His-Avi-tagged fusions and purified using Ni-Sepharose 6 Fast Flow affinity purification and polished via gel filtration through a superdex hi-prep resin (GE Healthcare). The anti-SIRP $\alpha$ v1 specific antibody clone HEF-LB was generated as described in reference [23]. For crystallography, the IgV domain of SIRP $\alpha$ v1 and Fab fragments was generated as described [14].

\section{Humanization of antibodies}

Parental clones of hAB21 (AB21 and AB25) were isolated from SynVH, a transgenic chicken, and have fully human heavy chains but chicken light chains [14]. In order to humanize the chicken-derived light chains, chicken hypervariable region (HVRs) of AB25 were grafted onto human lambda light chain IGLV1, IGLV2 and IGLV3 frameworks, and chicken HVRs of hAB21 were only grafted onto human lambda light chain IGLV1 framework [24]. Combination of antibodies was generated from 4 humanized light chains with two heavy chains (derived from $\mathrm{AB} 21$ and $\mathrm{AB} 25$ respectively) in Expi293, purified and tested for SIRP binding. The top humanized antibody, with favorable expression and binding properties, was designated hAB21 and selected for further testing.

\section{Determination of $\boldsymbol{K}_{\mathrm{D}}$}

The binding affinities of $\mathrm{AB} 21$ and hAB21 to human SIPR $\alpha$ v1 and v2 were determined using direct immobilization of the antibodies (via GLC chip). All antibodies and proteins were used at their nominal concentrations determined by A280 absorbance and molar extinction coefficient. Analytes (human SIRP $\alpha$ v1 and v2) were injected in a "one-shot" kinetic mode and flowed over AB21 and hAB21 immobilized ( 1000 RUs) on GLC chips using ProteOn Amine Coupling Kit. For the immobilization step, GLC chip was activated with EDAC/ Sulpho-NHS 1:1 (Biorad) diluted $1 / 100$ for $300 \mathrm{~s}$ at 25 $\mu \mathrm{L} / \mathrm{min}$. AB21 and hAB21 were diluted to $80 \mathrm{nM}$ concentration in $10 \mathrm{mM}$ sodium acetate buffer $\mathrm{pH} 4.5$ and immobilized to the chip at $30 \mu \mathrm{L} / \mathrm{min}$ for $50 \mathrm{~s}$. Chip was inactivated with ethanolamine for $300 \mathrm{~s}$ at $25 \mu \mathrm{L} / \mathrm{min}$. The analytes (human SIRP $\alpha$ v1 and v2 protein) were injected in a "one-shot" kinetic mode at nominal concentrations of 10, 3.3, 1.1, 0.37, 0.12 and $0 \mathrm{nM}$. Association times were monitored for $90 \mathrm{~s}$ at $100 \mu \mathrm{L} / \mathrm{min}$, and dissociation times were monitored for $1200 \mathrm{~s}$. The surfaces were regenerated with a 2:1 v/v blend of Pierce IgG elution buffer $/ 4 \mathrm{M} \mathrm{NaCl}$. Biosensor data were doublereferenced by subtracting the interspot data (containing no immobilized protein) from the reaction spot data (immobilized protein), and then subtracting the response of a buffer "blank" analyte injection from that of an analyte injection. Double-referenced data were fit globally to a simple Langmuir model and the $K_{\mathrm{D}}$ value was calculated from the ratio of the apparent kinetic rate constants $\left(K_{\mathrm{D}}=k_{\mathrm{d}} / k_{\mathrm{a}}\right)$.

\section{Crystallization of anti-SIRPa Fab: SIRPa complexes}

A pure sample of anti-SIRP $\alpha$ Fab-SIRP $\alpha$ V1 complex at a concentration of $11.3 \mathrm{mg} / \mathrm{mL}$ in a buffer of $10 \mathrm{mM}$ Tris $\mathrm{pH} 7.4,50 \mathrm{mM} \mathrm{NaCl}$ was set for sitting drop vapor diffusion with sparse matrix crystallization screen kits available Qiagen. The condition and crystal form that gave quality diffraction leading to a complete dataset was 1 . 0.1 M Sodium Acetate $\mathrm{pH}$ 4.0, 0.2 M Ammonium Sulfate, 18\% (w/v) PEG 4000 (Cryo-protectant: 5\% v/v Ethylene Glycol). Even though the crystallization condition contained a high percentage of PEG 4000, ethylene glycol was added as cryo-protectant to protect the crystal form from deteriorating and/or forming ice during freezing. These samples were screened for protein X-ray diffraction at the NSLS-II 17-ID AMX beamline; yielding a dataset with diffraction of 2.27 Angstroms resolution. Further crystallography data collected are detailed in Additional file 1: Table S1. Structure PDB ID: 7KPG.

\section{Cell binding and blockade of CD47 binding to SIRPa cells}

For detection of cell binding, AB21 was fluorescently labeled with the Alexa Fluor 647 Protein Labeling Kit (Thermo Fisher Scientific) according to the manufacturer's instructions. 250,000 cells per well in staining buffer (PBS, $0.5 \%$ BSA or $2 \%$ FBS) were plated in 96-well plates (Falcon). Cells were first stained with fixable Live/Dead Stain (Invitrogen) and washed once in staining buffer prior to all binding assays.

To detect SIRPa binding to cells, $500 \mathrm{nM}$ Alexa Fluor 647-labeled AB21 was titrated 1:4 for seven dilutions and added to cells in $100 \mu \mathrm{L}$ volume of FACS buffer $(\mathrm{PBS}+0.5 \%$ BSA) supplemented with a cocktail of human Fc block (Miltenyi Biotec) or mouse Fc block (Biolegend), anti-CD14 (Biolegend) for human and cynomolgus PBMCs or anti-CD11b (Biolegend) for mouse splenocytes. After a 60-min incubation on ice, cells were washed twice in staining buffer and fixed in $0.5 \%$ paraformaldehyde.

To block CD47 binding to SIRP $\alpha$ on PBMCs, Alexa Fluor 647 labeled CD47Fc at a concentration of $500 \mathrm{nM}$ and 1:4 titration starting at $1 \mu \mathrm{M}$ of AB21 were added to cells. After a 60-min incubation on ice, cells were washed twice in staining buffer and fixed in $0.5 \%$ formaldehyde. 
Cells were analyzed on a FACS Canto II (BD Biosciences), with subsequent data analysis using Flowjo 10.7 .

\section{Cell lines}

4T1, CT26, Raji, MDA-MB-231 and DLD-1 cells were obtained from the American Type Culture Collection (ATCC). MC38 cells were obtained from MuriGenics. All cell lines were cultured according to standard protocols.

\section{Animals}

All mouse experiments except for MDA-MB-231 and batf3 $\mathrm{KO}$ mice were conducted according to protocols approved by Institutional Animal Care and Use Committee (IACUC) of ALX Oncology. Tumor model with MDA-MB-231 and batf3 KO mice were conducted in compliance with UTSW Human investigation and UTSW Institutional Animal Care and Use Committee protocols. Female Batf3 ${ }^{-1-}$ mice in the C57BL6/J background and NSG-SMG3 mice were purchased from The Jackson Laboratory. Female BALB/c, C57BL/6 and NOD-SCID animals, age 6-8 weeks old, were purchased from Charles River Laboratories International (Hollister, CA). All animals were housed according to institutional IACUC guidelines.

Female naïve cynomolgus monkeys (Macaca fascicularis) were provided by Charles River Laboratories. The inlife portion of the study was conducted by CRL's testing facility (Reno NV), and the animals were released to the CRL testing facility's colony at the end of the study.

\section{Generation of monocyte-derived macrophages and phagocytosis assay}

Human $\mathrm{CD}_{14}{ }^{+}$cells were purified from Trima residuals (Vitalant) with Ficoll-Paque Plus and negative selection (Monocyte Isolation Kit II, Miltenyi Biotec) according to the manufacturers' protocols. Monocyte-derived macrophages (MDM) were made by seeding 10 million CD14 ${ }^{+}$cells into $150 \mathrm{~mm}$ tissue culture dishes (Corning) in growth medium supplemented with $10 \%$ human $\mathrm{AB}$ serum (Corning) or $10 \% \mathrm{FBS}$ and $50 \mathrm{ng} / \mathrm{mL}$ MCSF. Cells were cultured for 7-11 days. Adherent cells were detached from culture plates with TrypLE Select (Thermo Fisher Scientific). Target cells (DLD-1) were labeled with the Celltrace CFSE Cell Proliferation kit (Thermo Fisher Scientific) according to the manufacturer's instructions. 100,000 target cells and 50,000 MDMs were incubated in ultra-low attachment U-bottom 96-well plates (Corning) with anti-SIRP $\alpha$ antibodies and the corresponding tumor-specific antibody for $2 \mathrm{~h}$ at $37{ }^{\circ} \mathrm{C}$. Cetuximab was added at a concentration of $0.01-0.1 \mu \mathrm{g} / \mathrm{mL}$.

For flow cytometry, cells were incubated in human FcR blocking reagent (Miltenyi Biotec) and stained with fluorochrome-labeled antibodies against CD33 (clone WM53, Biolegend) and CD206 (clone 15-2, Biolegend). To eliminate macrophage/target cell adhesion from analyses, antibody against CD326 (clone 9C4, Biolegend) was included. Furthermore, a pulse geometry gate of forward scatter signal area vs height was used to select for single cells. Fixable viability dye (Thermo Fisher Scientific) was used to identify live cells. Cells were acquired on a FACS Canto II flow cytometer (BD Biosciences) with subsequent analysis using FlowJo software. Percent phagocytosis indicates the percentage of viable CD33+ CD206+ macrophages that stain negative for CD326 and positive for CFSE. Where applicable, 4 parameter fit curves were generated with Prism 7 software (GraphPad).

\section{In vitro PBMC culture}

Peripheral blood mononuclear cells (PBMC) were isolated from Trima residuals of healthy individuals with Ficoll-Paque Plus. 500,000 PBMCs were incubated in U-bottom 96-well plates (Falcon) with anti-SIRP at a concentration of $10 \mathrm{ug} / \mathrm{mL}$ for $48 \mathrm{~h}$ at $37 \mathrm{C}$.

For quantification of PBMC subsets by flow cytometry, cells were incubated in human FcR blocking reagent and stained with a cocktail of fluorochrome-labeled antibodies against lin-(CD3, CD14, CD16, CD19, CD56) and HLADR. Fixable viability dye was used to identify live cells. After staining, cells were washed and fixed with 0.5\% paraformaldehyde in PBS. Prior to acquisition, absolute counting beads (Thermo Fisher) were added and samples were acquired with Canto II flow cytometer and analyzed using FlowJo software.

\section{Tumor studies}

Isoflurane anesthesia was used on mice to eliminate or minimize pain and distress during tumor implantation. $2 \times 10^{6} \mathrm{MC} 38,2 \times 10^{6} \mathrm{CT} 26,5 \times 10^{5} \mathrm{~B} 16 \mathrm{~F} 10$ and $5 \times 10^{5}$ $4 \mathrm{~T} 1$ cells were resuspended in 100ul of PBS or RPMI and implanted subcutaneously into the flank of female C57BL/6 mice for MC38 and B16F10 and BALB/c for CT26 and 4T1. $5 \times 10^{6}$ Raji cells were resuspended in 100 ul 1:1 PBS:Matrigel (Corning) and implanted subcutaneously in the flank of NOD-SCID mice.

When tumors reached an average of $50-180 \mathrm{~mm}^{3}$, as calculated with the formula volume $=\left(\right.$ width $^{2} \times$ length $) / 2$, mice were randomized into treatment groups. All treatments were dosed intraperitoneally (i.p.) or intratumorally. For xenograft models in NOD-SCID mice, rituximab was dosed at $3 \mathrm{mg} / \mathrm{kg}$ and $\mathrm{AB} 21$ at $10 \mathrm{mg} / \mathrm{kg}$, five times every 3 days. In syngeneic models, mice were treated with $10 \mathrm{mg} / \mathrm{kg}$ for CT26, MC38, B16F10 or $30 \mathrm{mg} / \mathrm{kg}$ for $4 \mathrm{~T} 1 \mathrm{of}$ clone $\mathrm{AB} 21,10 \mathrm{mg} / \mathrm{kg}$ anti-PD-1 (BioXcell, clone RMP1-14) and $2 \mathrm{mg} / \mathrm{kg}$ (MC38 models) anti-PDL1 (murine IgG1, ALX Oncology). For intratumoral 
injections, $50 \mu \mathrm{g}$ of $\mathrm{AB} 21$ was given four times every 3 days.

For re-challenge experiments, treated mice with complete tumor eradications were re-challenged with either $2 \times 10^{6}$ MC38 cells on one flank or $0.5 \times 10^{6}$ B16F10 tumor cells on the opposite flank. Age-matched naïve mice were used as control.

For cellular depletion experiments, mice were dosed intraperitoneally with 250 ug of either anti-CSF1R (BioXcell, clone AFS98), anti-CD8b (Bioxcell, clone 53-5.8) or anti-GR1 (BioXcell, clone RB6-8C5) on days 2, 5, 10 and 15 post-tumor implantation. Confirmation of cellular depletion was performed on tumor and spleen of spare cellular depleted mice on days 1, 3, 4 and 8 post-injection by flow cytometry using anti-CD45 (Biolegend, clone 30-F11), anti-CD3 (Biolegend, clone 145-2C11), antiCD8 (Biolegend, clone 53.6.7), anti-CD11b (ebioscience, clone M1/70), anti-Ly6C (Biolegend, clone 145-2C11), MHCII (ebioscience, clone M5/114.15.2) and F4/80 (Biolegend, clone BM8).

Humanized mice were generated with 4-week NSGSGM3 female mice and irradiated with 100 cGy (X-ray irradiation with X-RAD 320 irradiator) 1 day prior to CD34+ cells transfer. Irradiated mice were treated with Bactrim (Aurora Pharmaceutical LLC) water for 2 weeks. Cord blood was obtained from UT Southwestern (UTSW) Parkland Hospital. Human CD34+ cells were purified from cord blood by density gradient centrifugation (Ficoll ${ }^{\circledR}$ Paque Plus, GE healthcare) followed by positive immunomagnetic selection with anti-human CD34 microbeads (Stem Cell). 10 $0^{5}$ CD34+ cells were intravenously injected into recipient mice.

12 weeks after engraftment, humanized mice with over $40 \%$ human $\mathrm{CD} 45^{+}$cells reconstitution and age and sex matched non-humanized mice were inoculated with $2 \times 10^{6}$ MDA-MB-231 tumor cells subcutaneously on the right flank. Tumor volumes were measured by length $(a)$, width $(b)$ and height $(c)$ and calculated as tumor volume $=a b c / 2.8$ days later when tumors were around 50 $\mathrm{mm}^{3}$, mice were intratumorally treated with $50 \mu \mathrm{g} \mathrm{AB} 21$, HEF-LB or PBS, four time every 3 days.

\section{T1 Lung metastasis quantification}

$\mathrm{BALB} / \mathrm{c}$ mice were implanted with $4 \mathrm{~T} 1$ cells and lungs were harvested 8-9 days post-last injection for metastatic nodule quantification. In brief, lungs were harvested in ice-cold 1xPBS, minced into small pieces then transferred into digestion solution consisting of $2 \mathrm{mg} / \mathrm{mL}$ collagenase type $\mathrm{V}$ (Worthington) supplemented with $50 \mathrm{ug} / \mathrm{mL}$ DNAse (Sigma) and incubated for $2 \mathrm{~h}$ in a 37C incubator with end-over-end rotation. Suspension was transferred into 70 -um strainer, washed once in $1 \times$ PBS then transferred into $10 \mathrm{~mL}$ selection media consisting of RMPI
1640 supplemented with $10 \%$ FBS, penicillin-streptomycin and $10 \mathrm{ug} / \mathrm{mL}$ 6-thioguanine (Sigma). Three to four 1:10 serial dilutions were plated either in 6-well plates or $10-\mathrm{cm}$ dishes and cultured for $10-14$ days at $37 \mathrm{C}, 5 \%$ $\mathrm{CO}_{2}$. Metastatic plaques were then fixed in methanol for $5 \mathrm{~min}$ at room temperature, re-hydrated in distilled water then stained with $0.03 \%$ methylene blue (Sigma) for $5 \mathrm{~min}$ at room temperature. Dye was then discarded, plate was rinsed gently with distilled water and allowed to air-dry prior to counting plaques.

\section{Immunophenotyping}

For immune response monitoring in tumor-bearing mice, anti-SIRP $\alpha$ was dosed either three times in combination with anti-PD-1, or twice with anti-SIRP $\alpha$ and once with anti-PD-1, all injections were administered i.p 3 days apart at $10 \mathrm{mg} / \mathrm{kg}$.

Spleens and tumors were harvested either 2 or 3 days post-last injection for immunophenotyping. Spleens were processed into single-cell suspension in ice-cold PBS, lysed with ACK lysis buffer (Gibco), washed twice and re-suspended in PBS supplemented with $2 \%$ FBS. Tumorderived single-cell suspensions were prepared using a cocktail of Collagenase I (Worthington), Collagenase IV (Sigma) and DNAse (Sigma) for $45 \mathrm{~min}$ at $37^{\circ} \mathrm{C}$. Cell counts were performed using ViCell counter (Beckman Coulter) for spleen and lymph node and trypan blue exclusion with hemocytometer for tumor. Aliquots of 1-2 $10^{6}$ cells were either used for cell-surface antigen staining or stimulation for cytokine assessment. For surface staining, cells were stained with LIVE/DEAD fixable dye (Thermo Fisher), followed by mouse Fc-block (Biolegend) and subsequently stained with antibodies according to cell-type specific antibody panels for at least $30 \mathrm{~min}$ at $4{ }^{\circ} \mathrm{C}$. CD4 clone GK1.5, CD8 clone 53-6.7, CD25 clone PC61, CD3 clone 145-2C11, CD45 clone 30-F11, CD47 clone MIAP301, NKp46 clone 29A1.4, PD1 clone J43, FoxP3 clone FJK-16s, Ki67 clone SolA15, Granzyme B clone QA16A02, CD44 clone IM7, CD62L clone MEL-14, TNFa clone MP6-XT22, IFNg clone XMG1.2, SIGLEC $\mathrm{H}$ clone 551, CCR7 clone 4B12, CD172 clone P84, CD86 clone GL-1, MHCII clone M5/114.15.2, GR-1 clone RB68C5, 33D1 clone 33D1, CD11b clone M1/70.15, CD11c clone N418, CD103 clone 2E7, Ly6C clone NH1.4, F4/80 clone BM8, CD24 clone M1/69. All flow antibodies were purchased from either Biolegend or Thermo Fisher.

For PMA/ionomycin ex-vivo stimulation to quantitate IFN $\gamma^{+}$cells, total splenic and tumor cells were plated at $1 \times 10^{6}$ cells/well in complete RPMI 1640 comprised of 10\% heat-inactivated FBS, 2\% Pen/Strep, 1\% Glutamax, $1 \%$ MEAA, $1 \%$ sodium pyruvate, $25 \mathrm{mM}$ HEPES and $5 \mu \mathrm{M}$ ß-mercaptoethanol supplemented with $50 \mathrm{ng} / \mathrm{mL}$ PMA (Fisher Scientific) and $1 \mu \mathrm{M}$ ionomycin (Sigma) in 
the presence of Golgi-Stop for at least $4 \mathrm{~h}$ at $37{ }^{\circ} \mathrm{C}, 5 \%$ $\mathrm{CO}_{2}$, and subsequently stained with antibodies to surface and intracellular markers. Samples were then acquired using Attune NxT (Thermo Fisher) or Canto II (BD). Analysis was performed using FlowJo 10.0 (BD) and tabulated using GraphPad Prism 7.3.

\section{HAB21 and soluble SIRPa serum ELISA}

Immulon 96-well ELISA plates (Thermo Fisher Scientific, 3855) were coated overnight with human wild type SIRP $\alpha$, variant 1 (ALX Oncology) in PBS. Plates were washed with Tris-Buffered Saline Tween-20 (TBST, $25 \mathrm{mM}$ Tris, $0.15 \mathrm{M} \mathrm{NaCl}, 0.05 \%$ Tween-20, pH 7.5) and blocked for $1 \mathrm{~h}$ with assay buffer (PBS, 1\% BSA, 0.05\% Tween-20, 0.25\% CHAPS, $5 \mathrm{mM}$ EDTA, $0.35 \mathrm{M} \mathrm{NaCl}$ ). Serum samples diluted a minimum of 1:50 in assay buffer or hAB21 standard curve protein (two-fold serial dilutions from 160 to $1.25 \mathrm{ng} / \mathrm{mL}$, in 1:50 normal cyno serum diluted in assay buffer) were added to blocked plates for $1 \mathrm{~h}$. Plates were washed with TBST. Standard curves and samples were incubated for $1 \mathrm{~h}$ with biotinylated goat anti-human IgG $(\mathrm{H}+\mathrm{L})$ antibody (Bethyl, A80-319B), washed with TBST, incubated for $30 \mathrm{~min}$ with HRPconjugated Avidin D (Vector, A2004), and washed with TBST. All plates were incubated with 1-Step Ultra TMB ELISA solution (Thermo Fisher Scientific, 34028) and the reaction was stopped with $0.16 \mathrm{M}$ sulfuric acid solution (Thermo Fisher Scientific, N600). Plates were read at an O.D. of $450 \mathrm{~nm}$ with a background reference reading at $570 \mathrm{~nm}$ on a SpectraMax i3 plate reader (Molecular Devices). Protein concentrations of serum samples were interpolated from the hAB21 standard curve with a 4-parameter fit curve using Prism software (GraphPad).

For the detection of soluble SIRP $\alpha$, similar assay to hAB21 serum ELISA was performed except for the following. $2 \mathrm{ug} / \mathrm{mL}$ anti-SIRP $\alpha$ mouse IgG1 antibody (AB136b, ALX Oncology, a non-CD47 blocking antibody that binds both cyno and human SIRP $\alpha$ with high affinity) in PBS was used to coat the plates. Cyno PK serum samples diluted 1:25 in assay buffer or SIRP $\alpha$ standard curve protein (ALX135, ALX Oncology, 25 to $0.024 \mathrm{ng} /$ $\mathrm{mL}$, diluted in assay buffer) were added to blocked plates for $1 \mathrm{~h}$. Pre-dose cynomolgus serum samples spiked with or without $200 \mathrm{ug} / \mathrm{mL}$ of anti-SIRP $\alpha$ human IgG1 antibody were run as controls since most of the PK samples contained at least $200 \mathrm{ug} / \mathrm{mL}$ anti-SIRP $\alpha$ human IgG1 antibody. After incubating samples for $1 \mathrm{~h}$ in the ELISA, plates were washed with TBST. $5 \mathrm{ug} / \mathrm{mL}$ anti-SIRP $\alpha$ human IgG1 kick-off Fab $+6 \times$ His tag (AB115f, ALX Oncology, binds both cynomolgus and human SIRP $\alpha$ with high affinity) was added to samples for $1 \mathrm{~h}$. Plates were washed with TBST. Samples were incubated for $1 \mathrm{~h}$ with $0.15 \mathrm{ug} / \mathrm{mL}$ rabbit anti- $6 \times$ His Tag HRP conjugated antibody (abcam cat. \# ab1187).

\section{HAB21 receptor occupancy}

For the analysis of receptor occupancy, $75 \mu \mathrm{L}$ aliquots of whole blood sample were washed in $1.5 \mathrm{~mL}$ FACS buffer (PBS, Thermo Fisher Scientific $+0.5 \%$ bovine serum albumin, Sigma) and stained with fluorochrome-conjugated antibodies against CD14 (M5E2, Biolegend) and HLA-DR (L243, Biolegend), fixable viability dye eFluor 506 (Thermo Fisher Scientific), and FcR blocking reagent, human (Miltenyi Biotec). SIRP $\alpha$ occupancy was detected using labeled SIRP $\alpha$ antibodies which would compete with test article for binding to SIRP $\alpha$. For detection of SIRP $\alpha$ occupancy, Alexa-Fluor 647 conjugated (Thermo Fisher Scientific) hAB21 was added to the lineage stains and cells were incubated at $4{ }^{\circ} \mathrm{C}$ for $1 \mathrm{~h}$. All stains were then washed in $1.5 \mathrm{~mL}$ FACS buffer and erythrocytes were lysed in $1.5 \mathrm{~mL}$ FACS lysing solution (BD Biosciences) for $10 \mathrm{~min}$ at room temperature. Cells were washed in $1.5 \mathrm{~mL}$ FACS buffer and resuspended in FACS buffer. Cells were analyzed by flow cytometry on a FACS Canto II (BD Biosciences).

Data were analyzed with FlowJo 10.4 software (Becton Dickinson). To measure SIRP $\alpha$ occupancy on monocytes, geometric mean fluorescence intensity (MFI) in the Alexa-Fluor 647 channel was determined for $\mathrm{CD}_{14}{ }^{+} \mathrm{HLADR}^{+}$cells. To calculate percent SIRP $\alpha$ occupancy, this value was normalized to the MFI for the predose timepoint as follows: MFI was calculated as a percentage of MFI at the predose timepoint. This number was subtracted from $100 \%$, with the result being the percent occupancy. Thus, MFI greater than or equivalent to the predose level is reported as zero percent occupancy and MFI equivalent to background is reported as $100 \%$ occupancy. All samples for which SIRP $\alpha$ staining was equivalent to or greater than staining of predose samples were considered to have no occupancy.

\section{Cynomolgus monkey study}

The in-life of monkey study was conducted by Charles River Laboratories (Reno, NV). The study was performed in accordance with the standard operating procedures and Good laboratory Practices (GLP). Male cynomolgus monkeys ( $n=2$ /group) of Chinese origin were administered hAB21 on Days 1 and 8 for a total of 2 intravenous doses at doses 10 and $30 \mathrm{mg} / \mathrm{kg}$ by slow bolus IV injection. Hematology was assessed by Charles River Laboratories and were collected from all animals on Days-4, 4, 8, 15, and 22. For PK bioanalysis, serum was collected from animals at the following time points: 0 (predose), 1, 3, 8, 24, 72, and $168 \mathrm{~h}$ postdose on Day 1. On Day 8, serum was collected from 
animals at the following time points: $1,3,8,24,72$, 168 h, Day 18 and D22 postdose. For receptor occupancy assay, blood samples were drawn and collected for all animals at the following time points: predose (Day-4), 4, 24, and $72 \mathrm{~h}$ after the Day 1 dose; predose, 4, 24, 72, and $168 \mathrm{~h}$ after the Day 8 dose; Day 18 and Day 22.

\section{Results}

We previously described a family of anti-SIRP $\alpha$ antibodies that antagonize SIRP $\alpha$ through competition for the CD47-binding site located on the IgV domain of SIRP $\alpha$ [22]. The anti-SIRP $\alpha$ blocking antibody clone AB21 was discovered from immunized SynVH chickens, which contain human $\mathrm{V}_{\mathrm{H}}$ immunoglobulin (Ig) repertoires paired with the natural chicken light chain repertoires [25]. The chimeric antibody AB21 binds to human SIRP $\alpha$ v1 and v2 alleles with picomolar affinity (Fig. 1a),
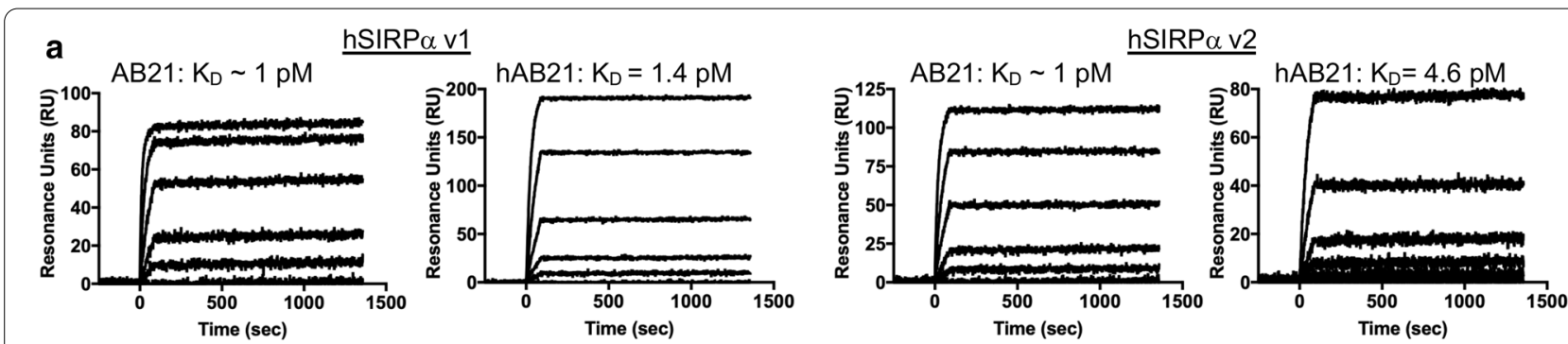

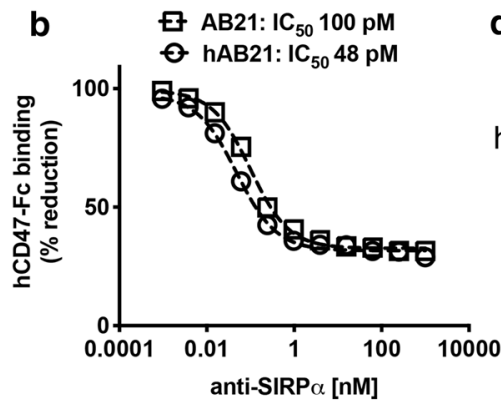

C

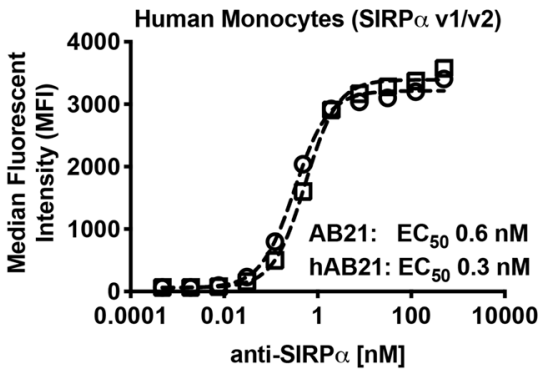

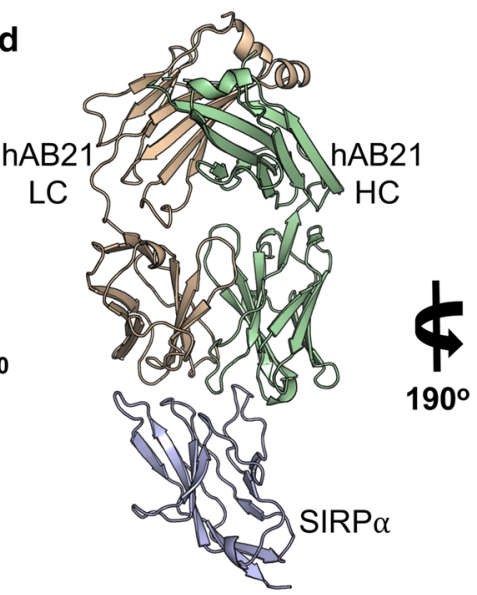

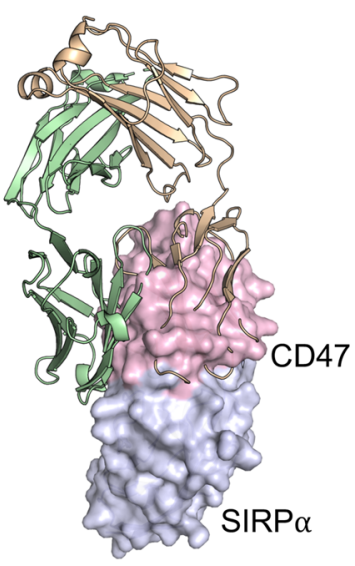

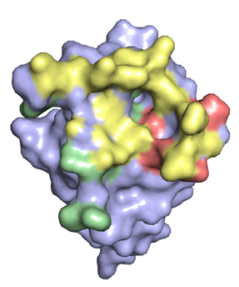

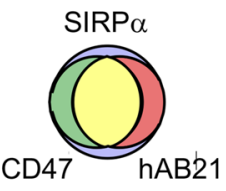

Fig. 1 Pan-allelic and species cross-reactive antibody, hAB21, binds SIRPa with high affinity and blocks CD47-SIRPa interaction. a Binding affinities (pM) of AB21 and humanized hAB21 to human SIRPa v1 and v2 were determined by SPR. $\mathbf{b}$ Binding curves of hCD47 on CD14 ${ }^{+}$monocytes in the presence of titrated AB21 and hAB21. PBMCs were incubated with $500 \mathrm{nM}$ fluorescent hCD47-FC and increasing concentration of AB21 and hAB21 at $4{ }^{\circ} \mathrm{C}$ for $60 \mathrm{~min}$, washed and evaluated by flow cytometry. Data are shown as ratio of CD14 ${ }^{+}$incubated with hCD47-Fc only. C Flow cytometry analysis of AB21 and hAB21 binding to human, cynomolgus and mouse CD14+ monocytes. Fluorescent-labeled AB21 and hAB21 were incubated in increasing concentration with cells at $4{ }^{\circ} \mathrm{C}$ for $60 \mathrm{~min}$, washed and evaluated by flow cytometry. Mean fluorescent intensity is measured. $\mathbf{d}$ Crystal structure of hAB21 anti-SIRPa Fab bound to the Ig-V domain of human SIRPa V1 (purple). CD47 domain (pink) was superimposed onto the crystallized complex. The adjacent Venn diagram and surface map depict the epitopes bound by CD47 (green) and hAB21 (red); shared epitopes bound by both CD47 and hAB21 to SIRPa V1 are colored yellow accordingly 
potently blocks the interaction between CD47 and SIRP $\alpha$ (Fig. 1b), and cross-reacts with cynomolgus and murine SIRP $\alpha$ (Fig. 1c). Since clone AB21 contained the chicken light chain sequences, we carried out humanization as described in the Materials and Methods to derive the humanized version, named hAB21. Humanized AB21 (hAB21) retains the SIRP $\alpha$ binding and antagonistic properties of the parental AB21 (Fig. 1a-c). The structure of a Fab version of the antibody in complex with the $\operatorname{IgV}$ domain of human SIRP $\alpha$ v1 was solved by X-ray crystallography (Fig. 1d). The hAB21 Fab binds to SIRP $\alpha$ at an epitope highly overlapping with that of CD47, with the VL domain overlapping with the majority of the CD47 binding site while the $\mathrm{VH}$ domain $\mathrm{CDR}-\mathrm{H} 3$ inserts into the central pocket of SIRP $\alpha$ that is crucial for CD47 binding, in agreement with the ability of hAB21 to completely block and antagonize the CD47-SIRP $\alpha$ interaction (Fig. 1d). AB21 and hAB21 were used interchangeably for subsequent experiments.

\section{Fc-domain Ig $G$ subclass influences the in vitro and in vivo activity of hAB21}

Antibody IgG subclass dictates $\mathrm{Fc} \gamma \mathrm{R}$ interactions that either promote (wild-type IgG1 and IgG4) or limit (IgG2 $\Delta \mathrm{a}$ and IgG1 ${ }^{\mathrm{FcDead}}$ ) antibody effector functions [2629]. Competition for FcyR binding between anti-SIRP $\alpha$ antibodies and anti-tumor antibodies may impact macrophage-mediated a ADCP. Therefore, we investigated the impact of IgG subclass on anti-SIRP $\alpha$ antibody-mediated enhancement of macrophage phagocytosis in vitro.

HAB21 was expressed as either a human IgG1, IgG4, $\operatorname{IgG} 2 \Delta \mathrm{a}$, or IgG1 ${ }^{\mathrm{FcDead}}$ subclass and macrophage phagocytosis of DLD-1 tumor cells opsonized with the antiEGFR antibody cetuximab alone or in combination with hAB21 was quantified by flow cytometry. Cetuximab alone promoted macrophage phagocytosis of DLD-1 tumors cells, and this was further enhanced in a dosedependent manner by combination with hAB21, but only when the Fc-domain of hAB21 was engineered to minimize binding to $F c \gamma R$ (Fig. 2a). HAB21 with an inactive IgG1 ${ }^{\text {FcDead }}$ or attenuated IgG2 $\Delta$ a Fc-domain enhanced cetuximab-mediated macrophage phagocytosis of DLD-1 tumor cells, whereas hAB21 with an active IgG1 or IgG4 Fc-domain demonstrated little to no impact on cetuximab-mediated phagocytosis (Fig. 2a). These results suggest that competition between hAB21 and cetuximab for macrophage Fc $\gamma R$ limits the phagocytosis enhancing effects of anti-SIRP $\alpha$ antibodies or that hAB21 with an active IgG simultaneously co-engages SIRP $\alpha$ and Fc $\gamma R$ on macrophages, resulting in a heterotrimeric interaction. This has been described as the "scorpion effect" [30] and this heterotrimer interaction would limit Fc $\gamma \mathrm{R}$ clustering by cetuximab, thereby decreasing pro-phagocytosis signals and reducing the enhancing effects of phagocytosis with hAB21 and cetuximab.

To further investigate the impact of IgG subclass on hAB21 activity, we cultured primary human peripheral blood mononuclear cells (PBMCs) with hAB21 containing different IgG subclasses for $48 \mathrm{~h}$ and quantified the numbers of T, B, monocytes, NK and DCs by flow cytometry. There was no significant change in the number of T, B, monocytes or NK cells (Additional file 1: Fig. S1A); however, PBMCs cultured with hAB21 containing an IgG1, IgG4, IgG2, or IgG2 $\Delta$ a Fc-domain had lower numbers of lineage negative $\left(\mathrm{CD}^{-}, \mathrm{CD}^{-} 9^{-}, \mathrm{CD}^{-} 6^{-}\right) \mathrm{HLA}-$ $\mathrm{DR}^{+}$DCs, whereas hAB21-IgG1 ${ }^{\mathrm{FcDead}}$ had limited impact on the numbers of respective DC lineage (Fig. 2b). Interestingly, although monocytes express higher levels of SIRP $\alpha$ than DCs (Additional file 1: Fig. S1B), we observed no changes in the number of monocytes present in PBMCs cultured with hAB21 irrespective of its IgG subclass.

Finally, we investigated the impact of Fc-domain IgG subclass on the in vivo antitumor activity of $A B 21$ in NOD SCID mice bearing subcutaneous human CD20 Raji tumor cells alone or in combination with rituximab. Treatment with rituximab alone substantially delayed tumor growth compared to the PBS control, whereas monotherapy with AB21 containing either an inactive (mouse IgG1 N297A) or active (mouse IgG2a) Fcdomain had minimal impact on tumor growth (Fig. 2c, $\mathrm{d}$ and Additional file 1: Fig. S2). The combination of AB21 containing an inactive Fc-domain with rituximab significantly improved anti-tumor activity compared to rituximab alone (Fig. 2c and Additional file 1: Fig. S2), consistent with the known impact of CD47-SIRP $\alpha$ antagonism on potentiating responses to antitumor antibody therapy [13, 31]. However, combination therapy using AB21 with an active Fc-domain decreased antitumor activity when compared to rituximab alone (Fig. 2d). Collectively, these data indicate that anti-SIRP $\alpha$ antibodies capable of triggering Fc effector functions limit the therapeutic activity both in vitro and in vivo through multiple mechanisms involving macrophage-mediated ADCP and DC depletion. We subsequently chose human IgG1 ${ }^{\text {FcDead }}$ as the Fc-domain for hAB21 and mouse IgG1_N297A as the Fc-domain for AB21 for further experimentation.

\section{HAB21 potentiates macrophage phagocytosis irrespective of SIRPa genotype}

Two allelic variants of SIRP $\alpha, \mathrm{v} 1$ and v2, are present in the human population at various frequencies and zygosities dependent on ethnicity [22]. Antagonism of both SIRP $\alpha$ alleles is essential to ensure all population can be targeted to maximize the phagocytosis promoting activities of anti-SIRP $\alpha$ blocking antibodies [22, 32]. To investigate 


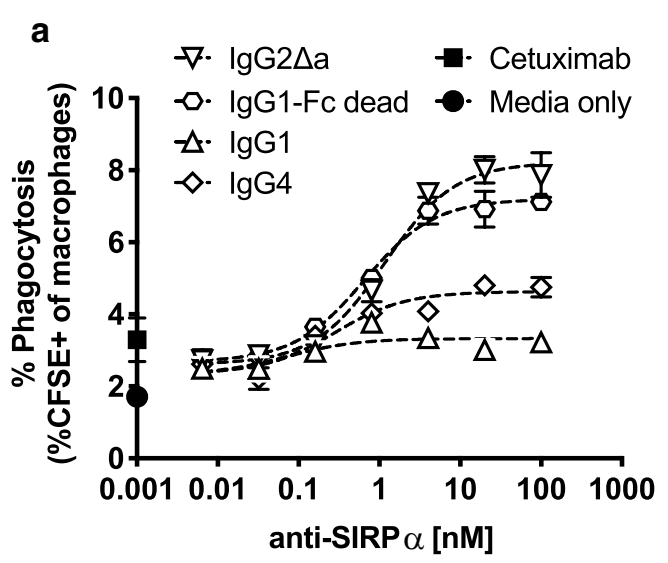

$\underline{\text { Raji }}$

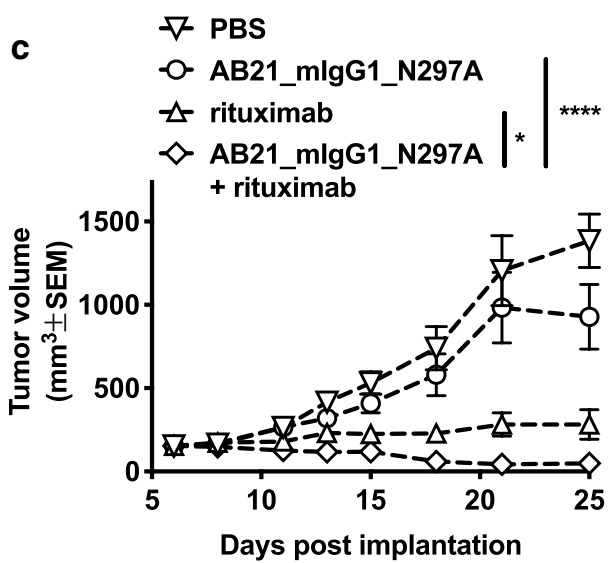

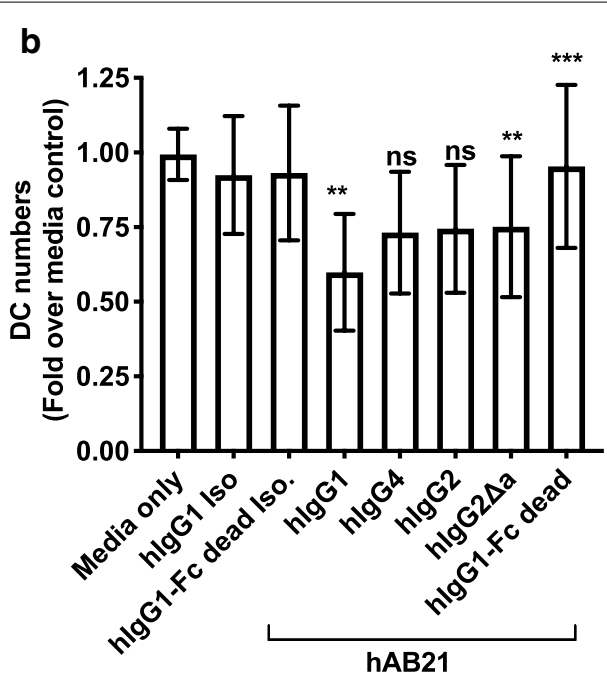

$\underline{\text { Raii }}$

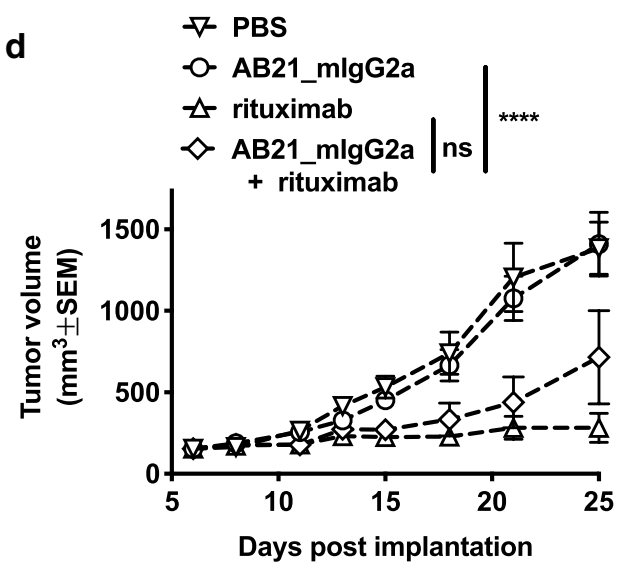

Fig. 2 IgG subclass influences the efficacy of anti-SIRPa antagonist antibodies in vitro and in vivo. a In vitro phagocytosis experiment with human MDMs cultured in the presence of human AB serum and DLD-1 cells in the presence of cetuximab at a constant concentration and titrated anti-SIRPa antibodies with different lgG subclass. Percent of macrophages that engulfed tumor cells is indicated on the $y$-axis. On the $y$-axis, closed circle indicates background phagocytosis observed with media only and closed square indicates cells treated with cetuximab only. $\mathbf{b}$ Relative dendritic cell numbers in human PBMCs after 48-h incubation with hAB21-lgG variants. Each bar indicates relative DC number as compared to media only. Statistics were performed using One-Way ANOVA, Dunnett's multiple comparisons. c, d Raji B-cell lymphoma cells were implanted subcutaneously on the right flanks of NOD-SCID mice. Mice with established tumors (average of $154 \mathrm{~mm}^{3}$ ) were randomized, $n=10 / \mathrm{group}$, and treated intraperitoneally with vehicle, rituximab, AB21 mlgG1_N297A (inactive) (c), AB21 mlgG2a (active) (d), or AB21 inactive or active + rituximab. Mice were treated five doses every 3 days. Statistics were performed using Two-Way ANOVA, Tukey's multiple comparisons test. ${ }^{*} p<0.05$, ${ }^{* *} p<0.01$, ${ }^{* * *} p<0.001$ and ${ }^{* * *} p<0.0001$

the influence of macrophage SIRP $\alpha$ genotype on the activity of hAB21, we derived human macrophages from primary human monocytes cultured in M-CSF (MDM), determined SIRP $\alpha$ v1 and v2 allelic status, and performed in vitro phagocytosis assays using $\mathrm{v} 1 / \mathrm{v} 1$ homozygous, $\mathrm{v} 1 /$ v2 heterozygous, or v2/v2 homozygous MDMs as effectors. HAB21 potently enhanced macrophage phagocytosis of DLD-1 tumor cells in a dose-dependent manner irrespective of SIRP $\alpha$ genotype with an $\mathrm{EC}_{50}$ of $\sim 0.2 \mathrm{nM}$, consistent with the high affinity binding of hAB21 to both SIRP $\alpha$ v1 and v2 variants (Fig. 3a). In contrast, the anti-SIRP $\alpha$ v1 specific antibody clone HEF-LB only promoted macrophage phagocytosis of DLD-1 cells by v1/ v1 homozygous macrophages, with limited or no activity with v1/v2 heterozygous or v2/v2 homozygous macrophages, respectively (Fig. 3a). Similarly, in humanized mice engrafted with human $\mathrm{CD} 4^{+}$cells from donors with v1/v2 SIRPA genotype bearing MDA-MB-231 triple 

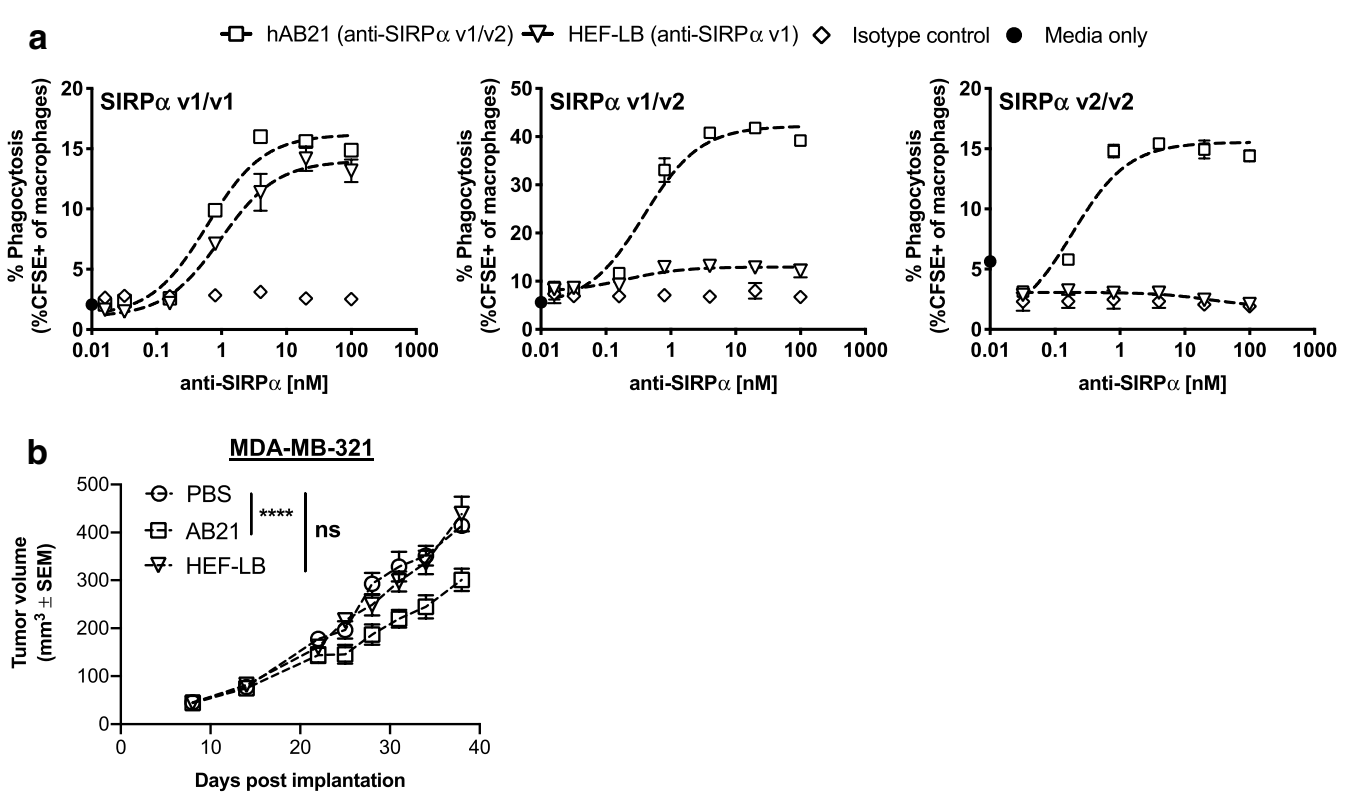

Fig. 3 hAB21 potentiates macrophage-mediated ADCP and delays tumor growth in SIRPa v1/v2 humanized mouse model. a In vitro phagocytosis experiment with human M-CSF derived MDMs and DLD-1 cells in the presence of titrated hAB21, HEF-LB or isotype control (FC inactive) antibodies. Percent of macrophages that engulfed CFSE-labelled tumor cells is indicated on the $y$-axis. On the $y$-axis, closed circle indicates background phagocytosis observed with media only. b MDA-MB-321 TNBC cells were implanted subcutaneously on the right flanks of humanized mice engrafted with human CD34+ cells from SIRPA v1/v2 donor. On day eight, mice with established tumors were randomized, $n=5$ mice/group, and treated intratumorally with PBS, clone HEF-LB, and AB21 mlgG1_N297A. Mice were treated four times every 3 days. ${ }^{* * *} p<0.0001$, statistics were performed using Two-Way ANOVA, Tukey's multiple comparisons test

negative breast cancer (TNBC) tumors, AB21 significantly decreased antitumor activity while clone HEF-LB had no impact on tumor growth (Fig. 3b).

\section{HAB21 monotherapy modestly delays tumor growth and is dependent on DC-mediated anti-tumor CD8+ T cell response}

We determined the anti-tumor activity of hAB21 monotherapy in C57BL/6 mice bearing syngeneic MC38 tumors. Treatment with hAB21 alone produced a modest but statistically significant delay in tumor growth compared to the PBS control group (Fig. 4). Depletion of macrophages and myeloid cells (anti-CSF1R) had little to no impact on the anti-tumor activity of hAB21, whereas depletion of neutrophils (anti-GR1) and CD8 ${ }^{+}$ (anti-CD8) T cells abrogated anti-tumor activity (Fig. 4) indicating a requirement for both innate and adaptive immunity. In batf3 ${ }^{-1-}$ mice that lack CD8 $\alpha^{+}$DCs [3] treatment with hAB21 had no effect on MC38 tumor growth, indicating a requirement for $\mathrm{CD} 8 \alpha^{+}$DCs. Collectively, these results indicate that both innate and adaptive immune responses are crucial to the antitumor activity of hAB21 monotherapy, consistent with previous studies identifying both neutrophils and DCs as important immune effector cells responsible for the efficacy of anti-CD47 therapy in syngeneic tumor models $[9,13,33]$.
Single agent activity of hAB21 in syngeneic models was restricted to MC38 tumors as we did not observe hAB21 activity in the more aggressive CT26, 4T1, or B16F10 tumors (Figs. 4, 5e, Additional file 1: Fig. S3).

\section{SIRPa antagonism improves the anti-tumor activity of T-cell checkpoint blockade in vivo}

Since hAB21 monotherapy produced a modest antitumor response requiring both innate and adaptive immunity, we determined if hAB21 activity could be further enhanced by combination with $\mathrm{T}$ cell checkpoint antagonists targeting the PD-1/PD-L1 interaction. Indeed, combination therapy with AB21 and anti-PD-L1 significantly delayed MC38 tumor growth compared to AB21 or anti-PD-L1 alone (Fig. 5a). Combination of AB21 with anti-PD-1 also resulted in a significant delay in tumor growth, which translated to a significant extension of survival and complete regression of MC38 tumors in 60\% $(6 / 10)$ of mice, whereas there were no complete cures in single agent $\mathrm{AB} 21$ or anti-PD-1 treatment groups (Fig. 5b). All surviving AB21 and anti-PD-1 combination therapy treated mice were protected against subsequent re-challenge with MC38 tumor cells (Fig. 5c), whereas the same surviving mice challenged contralaterally with the unrelated B16F10 tumor were not protected (Fig. 5d). These results demonstrate the development of 

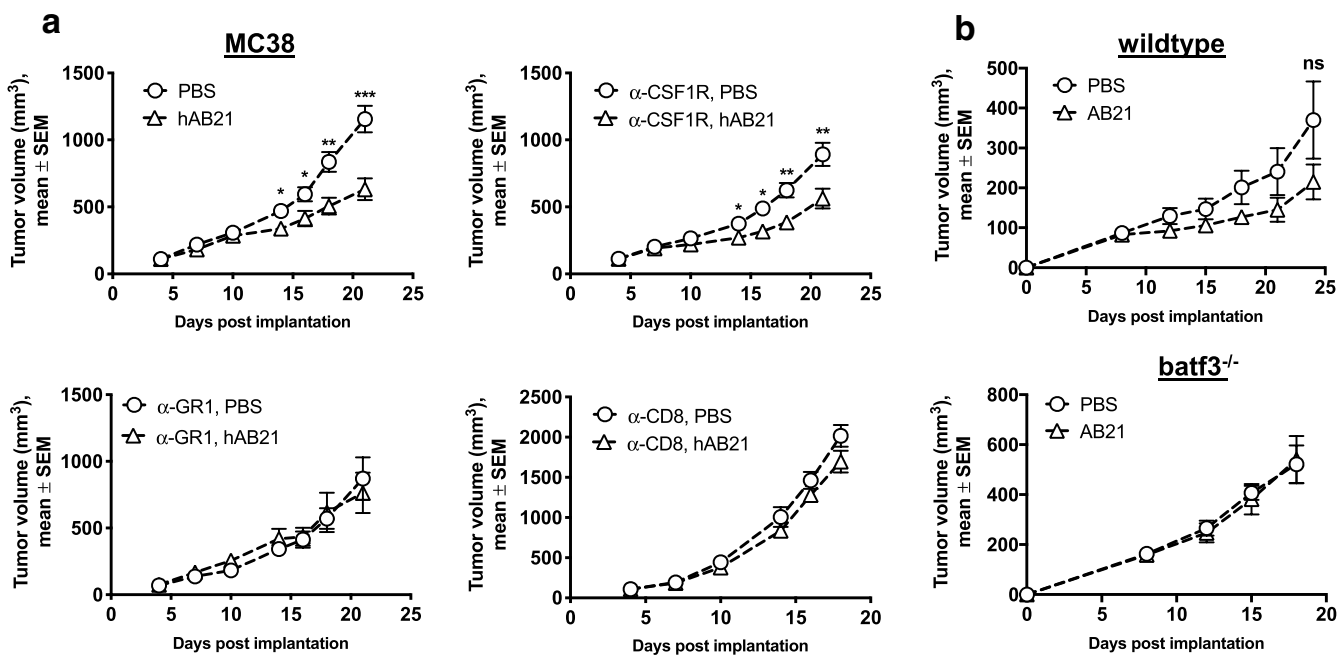

Fig. $4 \mathrm{CD}^{+}$T-cells, $C D 8^{+} \mathrm{DC}$ and granulocytes are necessary for in vivo efficacy of hAB21 monotherapy. a MC38 colon carcinoma cells were implanted subcutaneously in C57BL/6 mice. Two days post-implant, mice were treated with anti-CSF1R, anti-GR1 or anti-CD8 depleting antibodies. Mice with established tumors were randomized, $n=5$ mice/group, and treated intraperitoneally with PBS or hAB21. Mice were treated three times every 3 days. Depleting antibodies were dosed on days 2, 5, 10 and 15 post-implantation. Unpaired two-tailed t-test between PBS and hAB21 were determined for days indicated. ${ }^{*} p<0.05,{ }^{* *} p<0.01,{ }^{* * *} p<0.001$. b MC38 cells were implanted subcutaneously in wild type and Baft3-deficient C57BL/6 mice. Eight days post mice were randomized, $n=5$ mice/group, and dosed intratumorally with vehicle or AB21. Mice were treated four times, every 3 days

long-term, tumor-specific immune memory as a result of combination therapy. The growth of contralateral B16F10 tumors in mice surviving AB21 and anti-PD-1 combination therapy was delayed compared to age-matched naïve mice challenged with B16F10 (Fig. 5d), possibly due to the induction of a memory immune response against the MC38 tumor that may also respond to B16F10 tumor.

We further evaluated the efficacy of AB21 in combination with anti-PD-1 in BALB/c mice bearing subcutaneous CT26 tumors, a modestly immunogenic mouse colon carcinoma with variable responses to anti-PD-1 treatment [34]. Treatment with AB21 alone had no impact on tumor growth while treatment with anti-PD-1 alone trended toward a delayed tumor growth compared to the PBS control but did not reach statistical significance (Fig. 5e). Combination of anti-PD-1 with AB21 significantly delayed CT26 tumor growth compared to the PBS control and trended towards improved tumor control compared to the anti-PD-1 group (Fig. 5e).

The mouse 4T1 mammary tumor is poorly immunogenic, highly metastatic, and resistant to $\mathrm{T}$ cell checkpoint blockade [35]. BALB/c mice bearing subcutaneous 4T1 tumors were treated with AB21 and anti-PD-1 alone or in combination and primary tumor growth and metastatic burden in the lungs were quantified. Neither AB21 or anti-PD-1 given as a single agent or in combination had an effect on primary tumor growth (Additional file 1: Fig. S3A); however, AB21 monotherapy significantly reduced metastatic burden in the lung and a further reduction in metastatic burden in the AB21 and anti-PD-1 combination group, but did not reach statistical significance (Fig. 5f).

Finally, we evaluated the efficacy of AB21 in combination with an agonist antibody against the immune stimulatory molecule 4-1BB in C57BL/6 mice bearing subcutaneous B16F10 tumors, a poorly immunogenic, highly aggressive mouse melanoma that is resistant to anti-PD-1 therapy but partially responsive to anti4-1BB [36]. Treatment with AB21 alone had no effect on B16F10 tumor growth, whereas anti-4-1BB significant delayed tumor growth compared to the PBS control (Additional file 1: Fig. S3B). Combination of anti-4-1BB with AB21 did not improve antitumor responses against B16F10 (Additional file 1: Fig. S3B). Collectively, the in vivo efficacy studies indicate that AB21 combines with ICIs targeting PD-1 or PD-L1 to improve tumor control that leads to durable antitumor immunity against MC-38 and CT26 tumors. In more aggressive and less immunogenic tumor types such as B16F10 and 4T1, responses to the combination of AB21 with anti-PD-1 or anti-4-1BB are less pronounced compared to responses in MC38 and CT26 tumor models. 

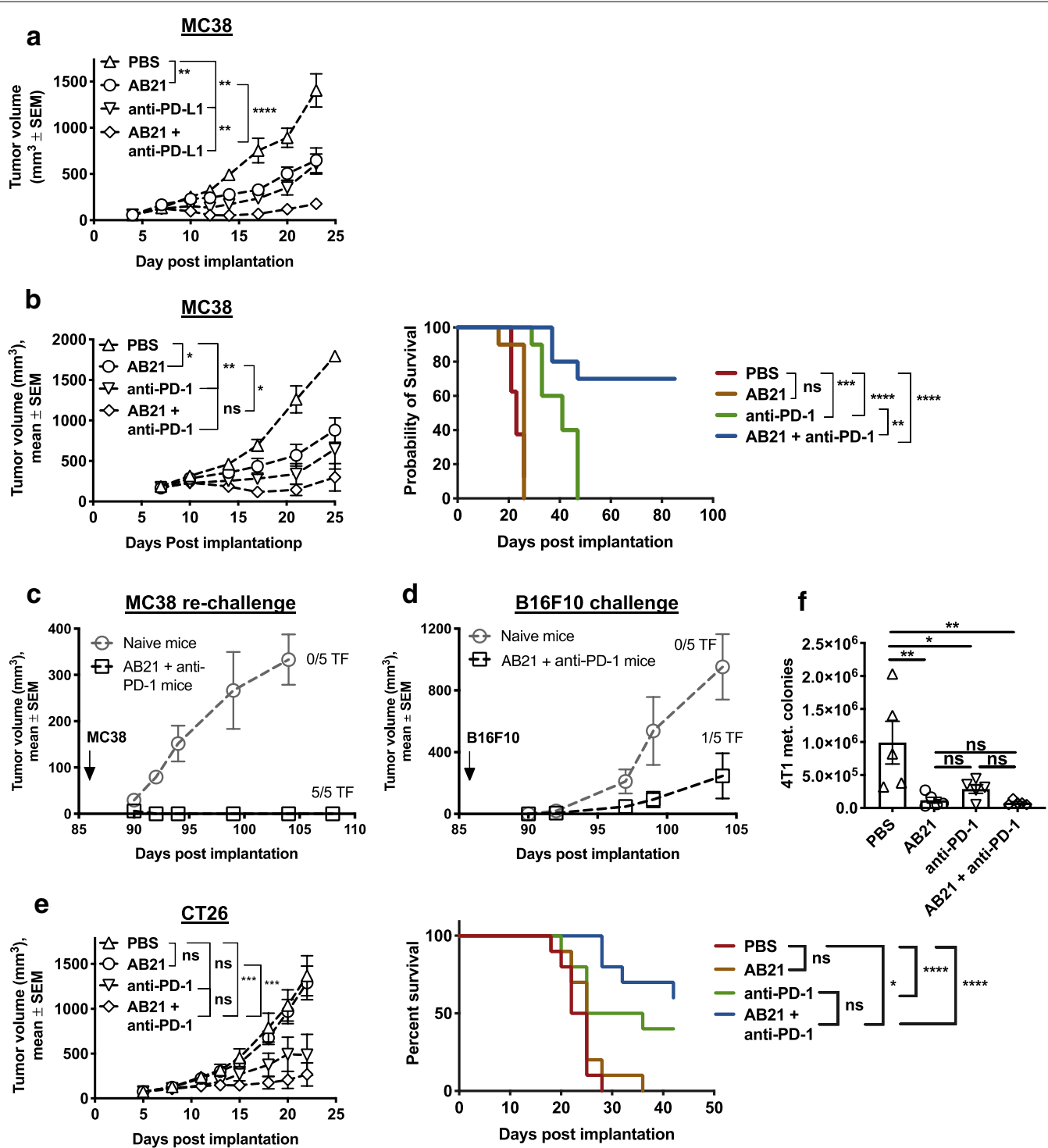

Fig. 5 AB21 potentiates the antitumor activity of anti-PD-L1 and anti-PD1. MC38 colon carcinoma cells were implanted subcutaneously in C57BL/6 mice. Mice with established tumors were randomized and treated intraperitoneally. a Mice were treated with PBS, AB21, anti-PD-L1 or AB21 and anti-PD-L1, two times every week for 3 weeks. Graph shows tumor curve with $n=10$ mice/group. Unpaired two-tail student's $t$-test on day 17 . b Mice were treated with PBS, AB21, anti-PD-1 or AB21 and anti-PD-1. Graphs show tumor growth of mice treated two times, every 3 days (left, unpaired two-tail $t$-test on day 25) and survival curves of mice treated three times every 3 days (Log-rank, Mantel-Cox test) of $n=10$ mice. c, $\mathbf{d}$ MC38 tumor-bearing mice treated with AB21 + anti-PD-1 and achieved complete eradication were rechallenged with MC38 (c) and B16F10 (d) 60 days post-eradication. Concurrently, MC38 and B16F10 cells were implanted subcutaneously into age-matched naïve C57BL/6 mice. Graphs show tumor growth of MC38 and B16F10 tumors. e Mice bearing CT26 tumors were treated with PBS, AB21, anti-PD-1 or AB21 + ant-PD-1, four times, every 3 days. Graphs show tumor growth of $n=10$ mice. Unpaired two-tail $t$-test on day 21 for growth curve and log-rank (Mantel-Cox) test for survival curves. $\mathbf{f}$ Total numbers of lung metastatic colonies in 4T1 tumor-bearing mice treated with PBS, AB21, anti-PD-1 or AB21 + anti-PD-1. The results are expressed as mean $\pm \operatorname{SD}(n=5) .{ }^{*} p<0.05,{ }^{* *} p<0.01,{ }^{* * *} p<0.001,{ }^{* * * *} p<0.0001$, ns indicates not significant

\section{AB21 induces DC activation and promotes $T$ cell effector functions in combination with anti-PD-1}

We conducted immunophenotyping using flow cytometry to directly access the cellular immune responses in MC38 tumor bearing mice treated with $\mathrm{AB} 21$ alone or in combination with anti-PD-1. MC38 tumor bearing mice were treated on days seven and ten with AB21 and one dose of anti-PD1 on day seven. Analysis of cellular responses in the spleen and tumor was performed 4 days post the final dose. Treatment with AB21 alone had little to no impact on the frequency of the various $\mathrm{T}$ cell subsets, NK cells, monocytes, $\mathrm{CD} 8^{+} \mathrm{DCs}$, or monocytic 
DCs (mDCs) in the spleen (Fig. 6, Additional file 1: Fig. S4A), but resulted in a significant reduction of $\mathrm{CD}^{-}$ DCs concomitant with an upregulation of the activation markers MHC class II and CD86 (Fig. 6a). The combination of AB21 and anti-PD-1 also activated and reduced the frequency of $\mathrm{CD} 8^{-} \mathrm{DCs}$ in the spleen, whereas treatment with anti-PD-1 alone had no effect (Fig. 6a) indicating that DC activation is a result of SIRP $\alpha$ blockade with $\mathrm{AB} 21 . \mathrm{CD}^{+} \mathrm{DCs}$ in the spleens of mice treated with AB21 alone or in combination with anti-PD-1 also displayed an activated phenotype and combination therapy resulted in a small but significant increase in the frequency of $\mathrm{CD}^{+}$DCs in the spleen (Fig. 6b). Furthermore, monocytes and $\mathrm{mDCs}$ were activated upon treatment with AB21 either alone or in combination with anti-PD-1 (Fig. 6d, e). Activation by AB21 was associated with a decrease in monocyte frequency and no change in $\mathrm{mDC}$ frequency in the spleen (Fig. 6d, e).

Within the tumor microenvironment, AB21 monotherapy and combination therapy with anti-PD-1 caused

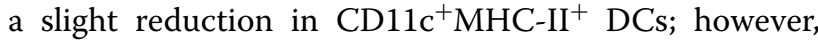
DC production of IL-12, a marker of activated DCs and a potent proinflammatory cytokine necessary for tumor control in response to ICIs [37], was significantly

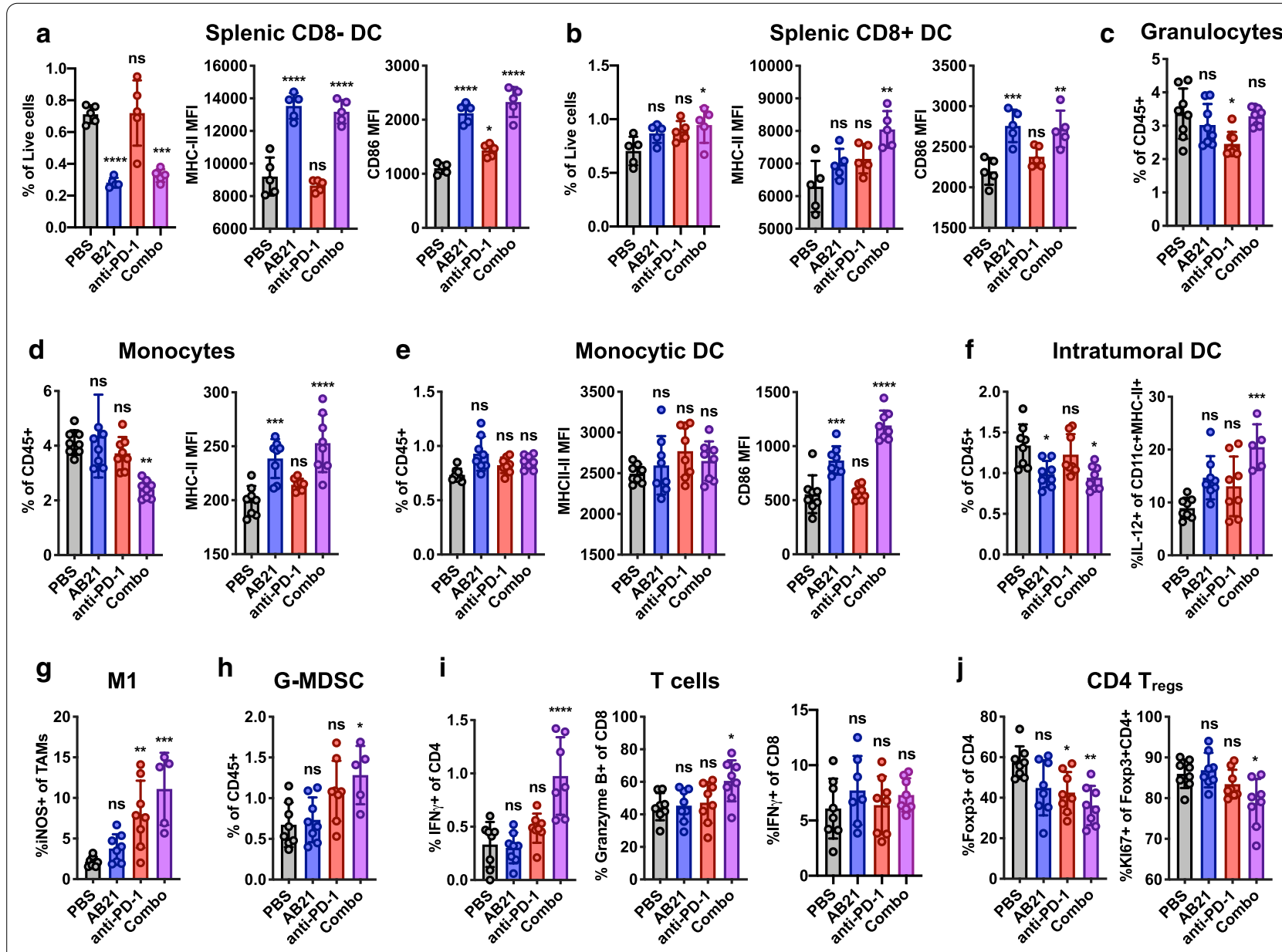

Fig. 6 Characterization of the lymphoid and myeloid compartments of tumors and spleen. MC38 colon carcinoma cells were implanted subcutaneously in C57BL/6 mice. Mice with established tumors were randomized and treated intraperitoneally with PBS, AB21, anti-PD-1 or combo (AB21 + anti-PD-1). $\mathbf{a}, \mathbf{b}$ Quantifications of splenic CD8 ${ }^{-}$and $C D 8^{+} \mathrm{CD} 11 \mathrm{C}^{\text {hi }} \mathrm{MHCl} \mathrm{I}^{+} \mathrm{DCs}$ as a proportion of live cells and expression of costimulatory molecules in the spleen. c-e Quantification of granuloctyes $\left(\mathrm{Gr} \mathrm{r}^{\text {mid }} \mathrm{CD} 11 \mathrm{~b}^{+}\right)$, monocytes $\left(\mathrm{Gr} \mathrm{h}^{\mathrm{hi}} \mathrm{CD} 11 \mathrm{~b}^{+}\right)$and monocytic DCs $\left(\mathrm{GR} 1^{\mathrm{hi}} \mathrm{CD} 11 \mathrm{c}^{+} \mathrm{CD} 11 \mathrm{~b}^{+} \mathrm{MHC}-\|^{+}\right)$as a proportion of live $\mathrm{CD} 45+$ cells and expression of costimulatory molecules in the spleen. $\mathbf{f}$ Quantification of DCs $\left(\mathrm{CD} 11 \mathrm{C}^{+} \mathrm{MHC}-\mathrm{II}^{+}\right)$as a proportion of live $\mathrm{CD} 45^{+}$cells and IL-12+ DCs in the tumor. $\mathbf{g}$ Quantification of iNOS+ expressing cells as a proportion of total TAMs (CD11 $\left.\mathrm{b}^{+} \mathrm{Gr} 1^{-} \mathrm{MHC}-\|^{+}\right)$in the tumor. $\mathbf{h}$ Quantification of granulocytic monocyte derived suppressor cells, G-MDSCs, (CD1 1 b ${ }^{+}$Gr ${ }^{\text {mid }}$ ) as a proportion of live $\mathrm{CD}_{4} 5^{+}$cells in the tumor. i Quantification of IFNg ${ }^{+}$cells as a proportion of CD4 and CD8 and Granzyme B as a proportion of CD8 in the tumor. $\mathbf{j}$ Quantification of Foxp3 ${ }^{+}$cells as a proportion of $\mathrm{CD} 4$ and $\mathrm{Ki} \mathrm{F}^{+}$cells as of Foxp $3^{+} \mathrm{CD} 4^{+} \mathrm{T}_{\text {regs }}$ in the tumor. Plotted as mean $\pm \mathrm{SD}$ and analyzed by Ordinary one-way ANOVA, Tukey's multiple comparisons test. ${ }^{*} p<0.05,{ }^{* *} p<0.01,{ }^{* * *} p<0.001$, ${ }^{* * * *} p<0.0001$, ns is not significant 
increased in response to combination therapy but not AB21 or anti-PD-1 monotherapy (Fig. 6f). Tumor-associated macrophages (TAMs) account for the majority of leukocytes within MC38 tumors and treatment with AB21, anti-PD-1, or the combination had no effect on TAM frequency (Additional file 1: Fig. S4B); however, iNOS production, a marker of M1, was significantly elevated in both the anti-PD-1 monotherapy and combination therapy groups (Fig. 6g). G-MDSC infiltration increased upon treatment with the combination of AB21 and anti-PD-1 (Fig. 6h). Additionally, surface expression of SIRP $\alpha$ on splenic and tumor myeloid cells was downregulated in response to $\mathrm{AB} 21$ treatment (both alone and in combination with anti-PD-1), but not in the anti-PD1 treatment group (Additional file 1: Fig. S4C). Downregulation of SIRP $\alpha$ by AB21 provides an additional mechanism of disrupting CD47-SIRP $\alpha$ signaling which likely contributes to the antitumor activity of AB21.

Potentiation of innate immune cell functions by AB21 facilitated further improvements in $\mathrm{T}$ effector cell responses to anti-PD-1 therapy with no changes to cell frequency (Additional file 1: Fig. S4D). Combination therapy promoted IFN $\gamma$ production by $\mathrm{CD}^{+} \mathrm{T}$ cells in the tumor and $\mathrm{CD}^{+} \mathrm{T}$ cells in the spleen and granzyme $\mathrm{B}$ production by $\mathrm{CD}^{+}{ }^{+} \mathrm{T}$ cells in the tumor (Fig. 6i, Additional file 1: S4A). In contrast monotherapy had limited impact on $\mathrm{T}$ cell effector functions. Furthermore, combination therapy significantly reduced the number of $\mathrm{CD} 4^{+}$ regulatory $\mathrm{T}$ cells $\left(\mathrm{T}_{\text {regs }}\right)$ in the tumor and decreased their proliferative capacity (Fig. 6j). The cellular responses to AB21 treatment are broadly in agreement with the cell depletion studies indicating both $\mathrm{DCs}$ and $\mathrm{CD} 8^{+} \mathrm{T}$ cells are indispensable for tumor control (Fig. 5). Collectively, these data indicate that SIRP $\alpha$ blockade with AB21 results in the repolarization of the myeloid-compartment, as evident by the increased activation phenotype and IL-12 production of the DCs as well as increased iNOS producing M1-like TAMs, resulting in an antitumorigenic phenotype.

\section{HAB21 demonstrates favorable PK, PD and tolerability profiles in monkeys}

HAB21 binds to both cynomolgus monkey SIRP $\alpha$ and human SIRP $\alpha$ with similar affinity (Fig. 1). Therefore, we conducted an exploratory study in cynomolgus monkey to determine the PK, PD and preclinical safety of hAB21. Monkeys received two weekly injections of vehicle control or hAB21-IgG1 ${ }^{\text {FcDead }}$ on days zero and seven at doses of either $10 \mathrm{mg} / \mathrm{kg}$ or $30 \mathrm{mg} / \mathrm{kg}$ and total serum antibody concentration, receptor occupancy, hematologic parameters and serum chemistry were determined. Systemic exposure to hAB21 increased linearly from the 10 to $30 \mathrm{mg} / \mathrm{kg}$ dose level with an $\mathrm{AUC}_{0168}$ of $17,783 \mathrm{ng} \mathrm{h} /$
$\mathrm{mL}$ and 48,635 $\mathrm{ng} \mathrm{h} / \mathrm{mL}$, a clearance of $0.35 \mathrm{~mL} / \mathrm{hr} / \mathrm{kg}$ and $0.29 \mathrm{~mL} / \mathrm{h} / \mathrm{kg}$, and a half-life of 5.3 days and 8.1 days, respectively (Fig. 7a). Complete target occupancy was observed in circulating monocytes within $3 \mathrm{~h}$ of dosing at both dose levels that persisted for 7 days post the first dose (Fig. 7b, c) and 14 days post the second dose at the $30 \mathrm{mg} / \mathrm{kg}$ dose (Fig. 7c). Accelerated clearance and the concomitant loss of target occupancy were observed in monkeys that received the $10 \mathrm{mg} / \mathrm{kg}$ dose (Fig. 7b) at time points on Day 14 and beyond, suggestive of an antidrug antibody (ADA) response to human proteins.

Proteolysis and release of soluble SIRP $\alpha$ from cell-surface expression has been demonstrated in cultured cells [38]. To investigate the presence of soluble SIRP $\alpha$ and potential impact of soluble SIRP $\alpha$ on PK of anti-SIRP $\alpha$ antibodies in the monkey studies, we used non-cross blocking antibodies to capture and measure free and antibody-bound soluble SIRP $\alpha$ in the serum. In all dosed monkeys, soluble SIRP $\alpha$ was detected to be present and accumulates during the course of the study as compared to predose levels (Fig. 7d). There is a 50-fold increase in soluble SIRP $\alpha$ as compared to predose after the first dose at both 10 and $30 \mathrm{mg} / \mathrm{kg}$. Post the second dose, the fold increase in soluble SIRP $\alpha$ reaches 200 -fold at the $30 \mathrm{mg} /$ $\mathrm{kg}$ dose and back to low levels by 14 and 21 days at the $10 \mathrm{mg} / \mathrm{kg}$ dose (Fig. 7d). The concentration of soluble SIRP $\alpha$ correlates with the PK of hAB21 (Fig. 7a), indicating accumulation of circulating soluble SIRP $\alpha$ due to decrease clearance while bound to hAB21.

No adverse findings for clinical signs, hematology and serum chemistry related to SIRP $\alpha$ blockade by hAB21 were observed at either dose level (Fig. 7e-h). No significant changes in red blood cells (Fig. 7e) and platelets (Fig. 7f) were observed. In addition, monocytes and neutrophils, which express high levels of SIRP $\alpha$, remained unaffected by hAB21 treatment (Fig. 7g, h). Collectively the data indicate that hAB21 is safe and well-tolerated in cynomolgus monkeys at repeated doses up to $30 \mathrm{mg} / \mathrm{kg}$ with linear PK and full target occupancy in blood.

\section{Discussion}

Blockade of the CD47-SIRP $\alpha$ interaction represents a promising approach to boost the antitumor activity of cancer immunotherapies when used as an adjuvant in antitumor antibody or ICI therapy. A variety of CD47 blocking antibodies or Fc-fusion proteins have shown objective responses in patients with advanced hematologic or solid tumor malignancies [14-17, 39, 40]. While a multitude of agents that target CD47 have been investigated in pre-clinical models and clinical trials, only a limited number of anti-SIRP $\alpha$ antibodies have been reported $[32,41]$. However, due to the lack of species cross-reactivity, no anti-SIRP $\alpha$ antibody has, to our knowledge, 


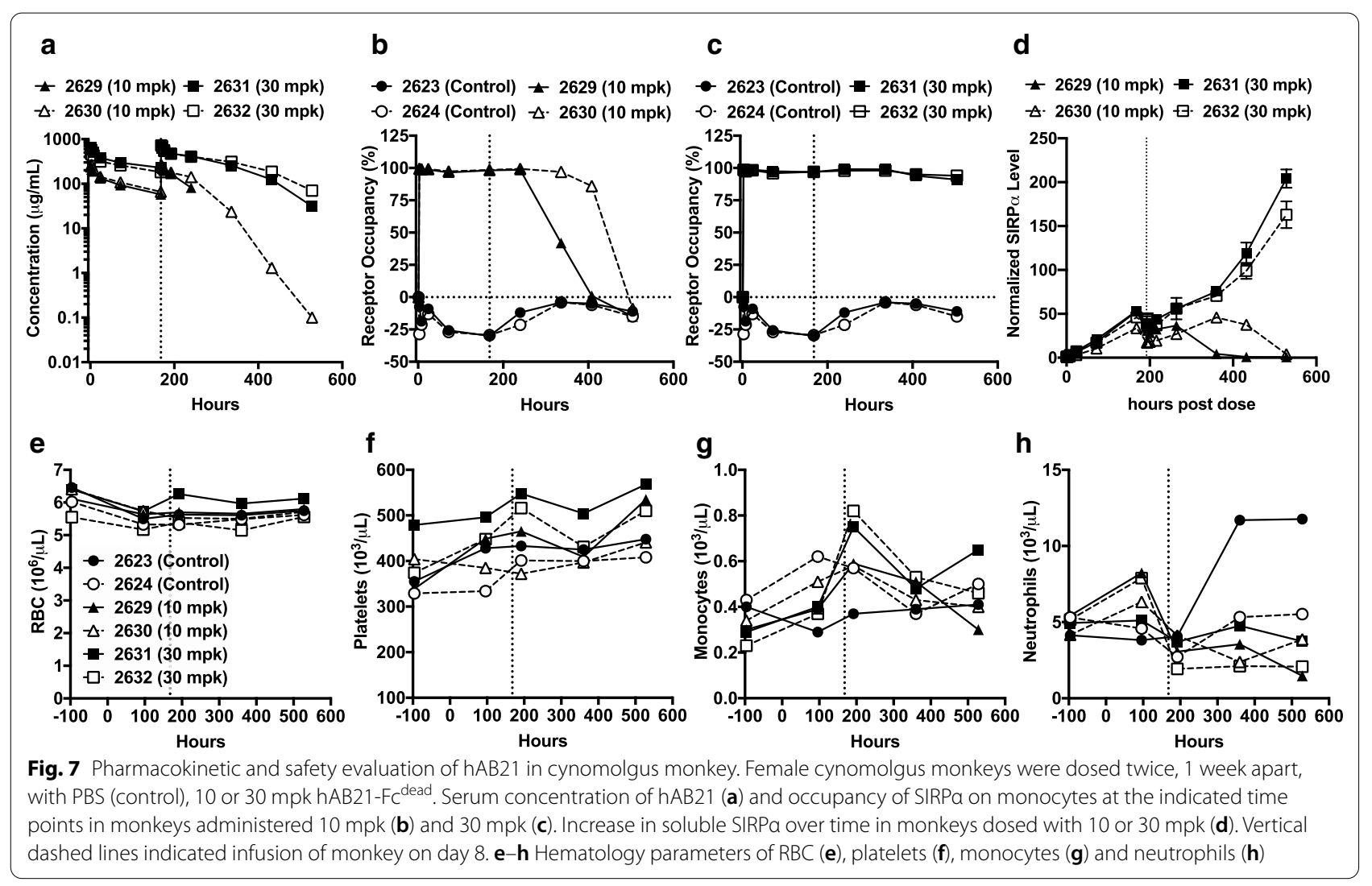

been investigated in both mouse and monkey to evaluate safety and efficacy. The development of antibodybased SIRP $\alpha$ antagonists suitable for clinical translation has been hindered in part by polymorphisms within the CD47-binding domain of SIRP $\alpha$, which necessitates pan-allele reactive anti-SIRP $\alpha$ antibodies for therapeutic intervention in diverse patient populations. Therefore, the impact of targeting SIRP $\alpha$ compared to CD47 was investigated as differences in target expression profile and function may result in divergent activities of anti-CD47 versus anti-SIRP $\alpha$ targeted therapies that could yield potentially distinct pharmacokinetic and safety profiles.

We previously identified anti-SIRP $\alpha$ antibodies from immunized chickens, which are phylogenetically distant from human, monkey, and mouse, which enabled the discovery of a diverse array of pan-allelic and species crossreactive anti-SIRP $\alpha$ antibodies [22]. Herein, we selected the anti-SIRP $\alpha$ antibody clone AB21 for humanization and further functional characterization due to its high affinity binding to both human SIRP $\alpha$ v1 and v2 alleles, comparable binding to cynomolgus monkey SIRP $\alpha$, cross-reactivity with various mouse SIRP $\alpha$ alleles, and ability to potently block the interaction between CD47 and SIRP $\alpha$. Allele cross-reactivity is an important design criterion for anti-SIRP $\alpha$ antibodies intended for clinical use. Several groups have reported the presence of multiple SIRPa alleles in the human population [32, 42]. However, in our analyses of 2535 individuals from 1000 Genome Project, we determined that only two dominant SIRP $\alpha$ alleles, $v 1$ and $v 2$, are present at various frequencies dependent on ethnicity [22]. Blockade of both SIRP $\alpha$ alleles is necessary to maximize efficacy; a single functional SIRP $\alpha$ variant can compensate for the antagonized variant. As demonstrated in Fig. 3, the v1 allele-specific anti-SIRP $\alpha$ antibody HEF-LB enhanced macrophagemediated ADCP only when v1/v1 homozygous macrophages were used as effectors. HEF-LB has little to no impact on ADCP mediated by v1/v2 heterozygous or v2/ v2 homozygous macrophages and on antitumor immunity by v1/v2 heterozygous donor (Fig. 3). In contrast, hAB21 is efficacious independent of SIRP $\alpha$ genotype (Fig. 3). SIRP $\alpha$ v1 specific antibodies, such as HEF-LB, would be limited to use in v1/v1 homozygote patient populations, which ranges from only $13.3-49.1 \%$ frequency among the global sub-populations [22]. Pan-allelic antibodies such as hAB21 can potentially impact the entire population, negating the need to stratify patients prior to therapy, a desirable property for clinical translation.

In addition to species and allele cross-reactivity, the choice of IgG subclass is an important consideration 
when designing therapeutic antibodies. The efficacy of both antitumor and immunomodulatory antibodies is highly dependent on Fc-domain engagement of FcyRs [43-45]. Fcy $\mathrm{R}$ interactions with tumor antigen specific antibodies are crucial for the induction of antitumor immunity [45] but can be detrimental to the activity of immunomodulatory antibodies due to unwanted depletion of antigen-positive effector cells [43]. Toxicity may also result from $F c \gamma R$ interactions that promote antibody-mediated destruction of undesirable cell types and tissues, as is the case for CD47-targeted therapies capable of engaging activating Fc $\gamma$ Rs [20]. CD47 is expressed broadly, including on RBCs and platelets. Hematological toxicities including thrombocytopenia and anemia are observed in patients treated with anti-CD47 antibodies capable of triggering FcyR-dependent effector functions $[19,20,39]$. We have previously demonstrated that safety liabilities associated with targeting CD47 can be mitigated by eliminating binding to $\mathrm{Fc} \gamma \mathrm{Rs}$, leading to the clinical development of ALX148 [13], a fusion protein consisting of a high-affinity SIRP $\alpha$ variant fused to an inactive Fc-domain [46].

To investigate the role of $F c \gamma R$ interactions on antiSIRP $\alpha$ antibody activity, we substituted the Fc-domain of hAB21 with various natural or engineered IgG Fcdomains that have differential binding to Fc $\gamma$ Rs. Inhibiting the CD47-SIRP $\alpha$ interaction generally enhances macrophage-mediated ADCP of tumor cells. However, we found that potentiation of ADCP was highly dependent on the hAB21 Fc-domain; hAB21 with active Fc-domains (IgG1 and IgG4) failed to enhance ADCP, whereas hAB21 with inactive Fc-domains potentiated ADCP (Fig. 2a). This differential activity was demonstrated to be due to competition between the antitumor antibody cetuximab and hAB21 for binding to effector cell FcyR. Our data corroborate Voets et al. [32] showing abrogation of rituximab induced phagocytosis when anti-SIRP $\alpha$ is expressed with an active Fc. Interestingly, DCs numbers were reduced significantly in PBMCs cultured in vitro with hAB21 containing active Fc-domains, whereas hAB21 with an inactive Fc-domain had no effect on DC numbers in PBMC cultures (Fig. 2b). Monocytes, despite expressing high levels of SIRP $\alpha$, were unaffected by hAB21 irrespective of IgG subclass (Additional file 1: Fig. S1). SIRP $\alpha$ expression on macrophages and DCs is downregulated by hAB21 (Additional file 1: Fig. S4C) and SIRP $\alpha$ downregulation can reduce SIRP $\alpha$ tonic signaling resulting in DC activation, maturation, and turnover, a mechanism previously reported in mice treated with an anti-SIRP $\alpha$ antibody $[47,48]$ and similar to what we observed in mice treated with hAB21 (Fig. 6). SIRP $\alpha$ downregulation by hAB21 may contribute to the DC depleting effect of hAB21; however, all anti-SIRP $\alpha$ antibodies regardless of subclass downregulate SIRP $\alpha$ but only hAB21 with active Fc-domains deplete DCs. We speculate that the DC depleting effect of hAB21 with an active Fc-domain is due to monocyte- and/or NK cellmediated killing of DCs opsonized with hAB21; however, we cannot rule out that the combination of SIRP $\alpha$ downregulation and $F c \gamma R$ signaling induced by hAB21 with an active Fc-domain contributes to DC maturation and subsequent apoptosis.

A similar relationship between FcyR-binding and hAB21 activity was observed in vivo. hAB21 with a mouse IgG2a Fc-domain, which preferentially binds activating Fc $\gamma$ Rs, reduced the antitumor activity of rituximab whereas hAB21 with a mouse IgG1-N297A Fc-domain (with limited $\mathrm{Fc} \gamma \mathrm{R}$ binding) enhanced rituximab antitumor activity. Although we did not investigate the in vivo mechanism responsible for these divergent activities, based on our in vitro results it is likely due to "scorpion effect", competition between rituximab and AB21 for binding to effector cell $\mathrm{Fc} \gamma \mathrm{R}$, unwanted depletion of DCs, or all. Thus, similar to CD47-targeted therapies, ablation of FcyR-dependent effector function is desirable when targeting SIRP $\alpha$, albeit for distinct reasons. Eliminating Fc-effector function from CD47 targeted therapies mitigates cytopenia [13], while eliminating effector function from anti-SIRP $\alpha$ antibodies is necessary to enhance macrophage-mediated ADCP and to prevent DC depletion in vitro.

We and others have demonstrated that blocking the CD47-SIRP $\alpha$ interaction has a profound impact on both antitumor antibody therapy and $\mathrm{T}$ cell checkpoint blockade, resulting in a coordinated innate and adaptive antitumor immune response mediated by multiple cell types including macrophages, dendritic cells, neutrophils, and $\mathrm{T}$ cells $[9,13,41,49,50]$. In most reported studies the target is CD47, and little is known about the in vivo pharmacology of targeting SIRP $\alpha$. Therefore, we investigated the impact of SIRP $\alpha$ antagonism on antitumor immunity in mouse tumor models using hAB21 as a monotherapy or in combination with an antitumor antibody or $\mathrm{T}$ cell checkpoint inhibitors. We selected hAB21 containing an inactive Fc-domain for all in vivo studies due to the impact of Fc-effector function on hAB21 activity in vitro. Similar to targeting CD47 [13, 31], SIRP $\alpha$ blockade with hAB21 improved responses to rituximab (anti-CD20) in the Raji human tumor xenograft model, indicating that a major mechanism of action of both anti-CD47 and antiSIRP $\alpha$ therapies in xenograft models, which lack NK, B and $T$ cells, is to enhance the antitumor activity of myeloid cells. Although we did not investigate the effector cells responsible for hAB21-mediated tumor eradication in the Raji xenograft model, Ring et al. demonstrated that neutrophils and macrophages are the main effector 
cells responsible for the anti-tumor activity of a SIRP $\alpha$ blocking antibody in human tumor xenograft models [41]. These data are consistent with a large body of evidence implicating phagocytes as the dominant effector cell responsible for the efficacy of agents that block the CD47-SIRP $\alpha$ interaction in xenograft models [31, 46, 51].

Disrupting the CD47-SIRP $\alpha$ interaction bridges innate and adaptive antitumor immune mechanisms $[9,13]$; therefore, we determined the activity of hAB21 in multiple syngeneic murine tumor models as a monotherapy or in combination with immune checkpoint inhibitors. These models encompass various levels of immunogenicity and sensitivity towards $\mathrm{T}$ cell checkpoint inhibition. As monotherapy, interfering with the CD47-SIRP $\alpha$ interaction generally has limited efficacy but is a powerful adjuvant to a variety of cancer immunotherapies $[31,46]$. Treatment with hAB21 alone had no effect on tumor growth in syngeneic 4T1, CT26, or B16F10 tumors (Fig. 5e and Additional file 1: Fig. S3). Modest hAB21 single agent activity was observed against MC38 tumors (Figs. 4a, 5a, b), which was dependent on the presence of $\mathrm{CD} 8 \alpha^{+} \mathrm{DCs}, \mathrm{CD} 8^{+} \mathrm{T}$ cells and neutrophils (Fig. 4). Depletion of neutrophils by anti-GR1 but not macrophages by anti-CSF1R prior to hAB21 treatment in immunocompetent mice showed no antitumor activity, suggesting cell depletion by anti-GR1 impacted hAB21induced antitumor activity. Although, anti-GR1 has been used extensively to deplete neutrophils in C57BL/6 mice, it does also bind $\mathrm{GR} 1+^{+}$non-neutrophils, specifically $\mathrm{CD} 8^{+} \mathrm{GR} 1^{+} \mathrm{T}$ cells $[52,53]$. The lack of antitumor activity with anti-GR1 depletion may be due to the elimination of $\mathrm{CD} 8^{+} \mathrm{GR} 1^{+} \mathrm{T}$ cells, known to secrete IFN $\gamma$, neutrophils or both cell types. $\mathrm{CD} 8 \alpha^{+} \mathrm{DCs}$ are indispensable for the production of a $\mathrm{CD}^{+}$antitumor $\mathrm{T}$ cell response [3] and DCs play a critical role in the responses to anti-CD47 targeted therapies $[9,13,33]$. Administration of hAB21 to MC38 tumor bearing mice resulted in DC activation in the spleen and tumor that when further combined with anti-PD-1/PD-L1 therapy promoted both $\mathrm{CD} 4+^{+}$and $\mathrm{CD}^{+} \mathrm{T}$ cell effector functions and reduced immunosuppressive $\mathrm{CD}^{+} \mathrm{T}_{\text {regs }}$ and TAMs leading to eradication of MC38 tumors and long-term, durable immunity. Similar mechanisms of MC38 tumor control have been reported for anti-CD47 antibodies [33, 54], and for ALX148, a CD47 blocking Fc-fusion protein [13], suggesting that the antitumor effects of targeting SIRP $\alpha$ broadly recapitulate that of CD47-targeted therapies despite differences in the ligand expression patterns and molecular and cellular functions of SIRP $\alpha$ and CD47.

Responses to the combination of hAB21 with anti-PD-1 or anti-4-1BB were less pronounced in more aggressive and less immunogenic tumors including CT26, 4T1, and B16F10 (Additional file 1: Fig S3). These results are consistent with additional studies that have investigated the combination of CD47 antagonists with checkpoint regulators in syngeneic mouse tumors [49]. In more aggressive and poorly immunogenic tumors, additional treatment modalities may be necessary to improve tumor control and eradication, such as triple combinations with tumor antigen specific antibodies, CD47/SIRP $\alpha$ antagonists, ICIs, vaccines, or chemotherapy $[49,55]$.

Due to the widespread expression of CD47, targeting SIRP $\alpha$ may overcome some obstacles associated with targeting CD47 $[32,56]$ such as the large antigen sink that promotes target mediated clearance of anti-CD47 therapies and off-tumor toxicities due to CD47 expression on RBCs and platelets by certain anti-CD47 therapeutics. We investigated safety and PK/PD of hAB21 in an exploratory toxicology study in cynomolgus monkey. No dose-dependent adverse clinical observations or changes in hematology and serum chemistry assessment were observed with hAB21 treatment (Fig. 7), whereas antiCD47 therapeutics capable of activating Fc $\gamma \mathrm{R}$-dependent effector functions causes dose-dependent cytopenia in NHPs and humans $[19,20]$. Administration of hAB21 with an inactive $\mathrm{Fc}$ at both $10 \mathrm{mg} / \mathrm{kg}$ or $30 \mathrm{mg} / \mathrm{kg}$ resulted in complete target occupancy on circulating monocytes and linear PK with a half-life of 5.3 days and 8.1 days, respectively. This contrasts with anti-CD47 antibodies or anti-CD47 Fc-fusion proteins which display non-linear PK and accelerated clearance at similar dose levels due to the large CD47 antigen sink [20]. However, soluble SIRP $\alpha$ was detected in the monkeys and accumulation observed during the course of the study (Fig. 7d). This is indicative of serum stabilization of the naturally produced soluble SIRP $\alpha$ by binding to the anti-SIRP $\alpha$ antibody. Soluble SIRP $\alpha$-bound antibody is not available for blocking cellular CD47-SIRP $\alpha$ interaction, potentially limiting the impact of the longer half-life of anti-SIRP $\alpha$ antibodies in comparison to anti-CD47 antibodies.

\section{Conclusion}

In summary, blockade of SIRP $\alpha$ with hAB21 potently enhances macrophage phagocytosis of tumor cells and promotes activation of DCs leading to the induction of adaptive antitumor $\mathrm{T}$ cell responses in tumor bearing mice, substantially improving responses to both antitumor antibody and immune checkpoint therapy. The in vitro and in vivo antitumor activity of hAB21 broadly recapitulates that of $\mathrm{CD} 47$ targeted therapies despite differences in ligand expression, binding partners, and function, validating the CD47-SIRP $\alpha$ axis as fundamental myeloid checkpoint pathway and its blockade as promising therapeutic intervention for treatment of human malignancies. 


\section{Supplementary information}

Supplementary information accompanies this paper at https://doi. org/10.1186/s13045-020-00989-w.

Additional file 1. Supplementary figures and table.

\section{Abbreviations}

ADA: Anti-drug antibody; ADCP: Antibody-dependent cellular phagocytosis; DC: Dendritic cell; FcyR: Fragment crystallizable gamma receptor; ICl: Immune checkpoint inhibitor; mDC: Monocytic dendritic cell; MDSC: Myeloid-derived suppressor cell; PBMC: Peripheral blood mononuclear cell; PK: Pharmacokinetic; SIRPa: Signal regulatory protein; TAM: Tumor-associated macrophage; TNBC: Triple negative breast cancer; Treg: Regulatory T cell.

\section{Acknowledgements}

The authors thank A.S. Wibowo and J. Carter from Helix BioStructures for help with X-ray crystallography and Sophia Randolph for discussion and critical reading of the manuscript.

\section{Authors' contributions}

TCK, JS, JP, and HIW conceived and guided the research. TCK, AC, OH, AZ, ES, $L D, D F$, and JS carried out the experiments. All authors analyzed and interpreted the data. TCK, AC, OH, and JTS wrote the manuscript. TCK, JS, JP, and HIW critically review and provided comments on the manuscript. All authors approved the manuscript.

\section{Funding}

The study was sponsored by ALX Oncology.

\section{Availability of data and materials}

All relevant data are within the paper and its Supplementary files. Structure information is provided in Protein Data Bank (PDB).

\section{Ethics approval and consent to participate}

In vivo studies were approved by the Institutional Animal Care and Use Committee of ALX Oncology and UTSW.

\section{Consent for publication}

Not applicable.

\section{Competing interests}

TCK, AC, OH, JTS, ES, LD, SEK, DF, SB, BH, JS, and HIW were all employed by ALX Oncology and are shareholders. JP is employed by ALX Oncology and is a shareholder.

\section{Author details}

${ }^{1}$ ALX Oncology, Burlingame, CA, USA. ${ }^{2}$ Department of Pathology, University of Texas Southwestern Medical Center, Dallas, TX, USA. ${ }^{3}$ Present Address: Tallac Therapeutics, Burlingame, CA, USA. ${ }^{4}$ Present Address: Genentech, South San Francisco, CA, USA. ${ }^{5}$ Present Address: Coherus BioSciences, Redwood City, CA, USA. ${ }^{6}$ Present Address: ProLynx Inc., San Francisco, CA, USA.

Received: 1 October 2020 Accepted: 2 November 2020 Published online: 30 November 2020

\section{References}

1. Sharma P, Allison JP. Immune checkpoint targeting in cancer therapy: toward combination strategies with curative potential. Cell. 2015;161(2):205-14

2. Ribas A, Wolchok JD. Cancer immunotherapy using checkpoint blockade. Science. 2018:359(6382):1350-5.

3. Hildner K, Edelson BT, Purtha WE, Diamond M, Matsushita H, Kohyama M, et al. Batf3 deficiency reveals a critical role for CD8alpha+ dendritic cells in cytotoxic T cell immunity. Science. 2008;322(5904):1097-100.
4. Jahchan NS, Mujal AM, Pollack JL, Binnewies M, Sriram V, Reyno L, et al. Tuning the tumor myeloid microenvironment to fight cancer. Front Immunol. 2019;10:1611.

5. Thorsson V, Gibbs DL, Brown SD, Wolf D, Bortone DS, Ou Yang TH, et al. The immune landscape of cancer. Immunity. 2018;48(4):812-830 e14.

6. Veglia F, Gabrilovich DI. Dendritic cells in cancer: the role revisited. Curr Opin Immunol. 2017;45:43-51.

7. Matlung HL, Szilagyi K, Barclay NA, van den Berg TK. The CD47-SIRPalpha signaling axis as an innate immune checkpoint in cancer. Immunol Rev. 2017:276(1):145-64

8. Veillette A, Chen J. SIRPalpha-CD47 immune checkpoint blockade in anticancer therapy. Trends Immunol. 2018;39(3):173-84.

9. Liu X, Pu Y, Cron K, Deng L, Kline J, Frazier WA, et al. CD47 blockade triggers $T$ cell-mediated destruction of immunogenic tumors. Nat Med. 2015;21(10):1209-15.

10. Latour S, Tanaka H, Demeure C, Mateo V, Rubio M, Brown EJ, et al. Bidirectional negative regulation of human $T$ and dendritic cells by CD47 and its cognate receptor signal-regulator protein-alpha: down-regulation of IL-12 responsiveness and inhibition of dendritic cell activation. J Immunol. 2001;167(5):2547-54.

11. Liu Y, Buhring HJ, Zen K, Burst SL, Schnell FJ, Williams IR, et al. Signal regulatory protein (SIRPalpha), a cellular ligand for CD47, regulates neutrophil transmigration. J Biol Chem. 2002;277(12):10028-36.

12. Pengam S, Durand J, Usal C, Gauttier V, Dilek N, Martinet B, et al. SIRPalpha/CD47 axis controls the maintenance of transplant tolerance sustained by myeloid-derived suppressor cells. Am J Transplant. 2019;19(12):3263-75.

13. Kauder SE, Kuo TC, Harrabi O, Chen A, Sangalang E, Doyle L, et al. ALX148 blocks CD47 and enhances innate and adaptive antitumor immunity with a favorable safety profile. PLoS ONE. 2018;13(8):e0201832.

14. Advani R, Flinn I, Popplewell L, Forero A, Bartlett NL, Ghosh N, et al. CD47 blockade by Hu5F9-G4 and rituximab in Non-Hodgkin's lymphoma. N Engl J Med. 2018;379(18):1711-21.

15. Weiskopf K. Cancer immunotherapy targeting the CD47/SIRPalpha axis. Eur J Cancer. 2017:76:100-9.

16. Chow LQM, Gainor J, Lakhani N, Chung H, Lee K-W, Lee J, et al. A phase 1 study of ALX148, a CD47 blocker, in combination with established anticancer antibodies in patients with advanced malignancy. Chicago: American Society of Clinical Oncology; 2019

17. Kim TM, Lakhani N, Gainor J, Kamdar M, Fanning P, Squifflet $P$, et al. A phase I study of ALX148, a CD47 blocker, in combination with rituximab in patients with non-Hodgkin lymphoma. Orlando: American Society of Hematology; 2019.

18. Eladl E, Tremblay-LeMay R, Rastgoo N, Musani R, Chen W, Liu A, et al. Role of CD47 in hematological malignancies. J Hematol Oncol. 2020;13(1):96.

19. Petrova PS, Viller NN, Wong M, Pang X, Lin GHY, Dodge K, et al. TTI-621 (SIRPaFc): A CD47-blocking innate immune checkpoint inhibitor with broad antitumor activity and minimal erythrocyte binding. Clin Cancer Res. 2017;23(4):1068-79.

20. Liu J, Wang L, Zhao F, Tseng S, Narayanan C, Shura L, et al. Pre-clinical development of a humanized anti-CD47 antibody with anti-cancer therapeutic potential. PLoS ONE. 2015;10(9):e0137345.

21. Wan HI, Chow LQM, Gainor J, Lakhani N, Chung H, Lee K-W, et al. Pharmacodynamic biomarker characterization of ALX148, a CD47 blocker, in combination with established anticancer antibodies in patients with advanced malignancy. National Harbor: Society for Immunotherapy of Cancer; 2019

22. Sim J, Sockolosky JT, Sangalang E, Izquierdo S, Pedersen D, Harriman W, et al. Discovery of high affinity, pan-allelic, and pan-mammalian reactive antibodies against the myeloid checkpoint receptor SIRPalpha. MAbs. 2019;11(6):1036-52.

23. Poirier N, Mary C, Vanhove B, Gauttier V, Thepenier V, Pengam S, inventors: OSE IMMUNOTHERAPEUTICS, assignee. New anti-SIRPa antibodies and their therapeutic applications. WO patent WO 2017/178653 A2. 2017 2017/04/14.

24. Pons J, Sim Bang J, Wan H, Kuo Tracy C-C, inventors; ALX ONCOLOGY INC, assignee. Antibodies against signal-regulatory protein alpha and methods of use. WO patent WO 2019/183266 A1. 2019 2019/03/20

25. Schusser B, Collarini EJ, Pedersen D, Yi H, Ching K, Izquierdo S, et al. Expression of heavy chain-only antibodies can support B-cell 
development in light chain knockout chickens. Eur J Immunol. 2016;46(9):2137-48.

26. Armour KL, Atherton A, Williamson LM, Clark MR. The contrasting IgGbinding interactions of human and herpes simplex virus Fc receptors. Biochem Soc Trans. 2002;30(4):495-500.

27. Xu D, Alegre ML, Varga SS, Rothermel AL, Collins AM, Pulito VL, et al. In vitro characterization of five humanized OKT3 effector function variant antibodies. Cell Immunol. 2000;200(1):16-26.

28. Shields RL, Namenuk AK, Hong K, Meng YG, Rae J, Briggs J, et al. High resolution mapping of the binding site on human lgG1 for FC gamma RI, Fc gamma RII, Fc gamma RIII, and FcRn and design of IgGI variants with improved binding to the Fc gamma R. J Biol Chem. 2001;276(9):6591-604

29. Morgan A, Jones ND, Nesbitt AM, Chaplin L, Bodmer MW, Emtage JS. The $\mathrm{N}$-terminal end of the $\mathrm{CH} 2$ domain of chimeric human $\lg \mathrm{G} 1$ anti-HLA-DR is necessary for C1q, Fc gamma Rl and Fc gamma RIII binding. Immunology. 1995;86(2):319-24.

30. Kurlander RJ. Blockade of Fc receptor-mediated binding to U-937 cells by murine monoclonal antibodies directed against a variety of surface antigens. J Immunol. 1983;131(1):140-7.

31. Chao MP, Alizadeh AA, Tang C, Myklebust JH, Varghese B, Gill S, et al. AntiCD47 antibody synergizes with rituximab to promote phagocytosis and eradicate non-Hodgkin lymphoma. Cell. 2010;142(5):699-713.

32. Voets E, Parade M, Lutje Hulsik D, Spijkers S, Janssen W, Rens J, et al. Functional characterization of the selective pan-allele anti-SIRPalpha antibody ADU-1805 that blocks the SIRPalpha-CD47 innate immune checkpoint. J Immunother Cancer. 2019;7(1):340.

33. Xu MM, Pu Y, Han D, Shi Y, Cao X, Liang H, et al. Dendritic cells but not macrophages sense tumor mitochondrial DNA for cross-priming through signal regulatory protein alpha signaling. Immunity. 2017;47(2):363-373 e5.

34. Wang S, Campos J, Gallotta M, Gong M, Crain C, Naik E, et al. Intratumoral injection of a $\mathrm{CpG}$ oligonucleotide reverts resistance to PD-1 blockade by expanding multifunctional CD8+T cells. Proc Natl Acad Sci USA. 2016:113(46):E7240-9.

35. Mosely SI, Prime JE, Sainson RC, Koopmann JO, Wang DY, Greenawalt DM, et al. Rational selection of syngeneic preclinical tumor models for immunotherapeutic drug discovery. Cancer Immunol Res. 2017;5(1):29-41.

36. Menk AV, Scharping NE, Rivadeneira DB, Calderon MJ, Watson MJ, Dunstane $D$, et al. 4-1BB costimulation induces $T$ cell mitochondrial function and biogenesis enabling cancer immunotherapeutic responses. J Exp Med. 2018:215(4):1091-100.

37. Garris CS, Arlauckas SP, Kohler RH, Trefny MP, Garren S, Piot C, et al. Successful anti-PD-1 cancer immunotherapy requires $T$ cell-dendritic cell crosstalk involving the cytokines IFN-gamma and IL-12. Immunity 2018:49(6):1148-1161 e7.

38. Londino JD, Gulick D, Isenberg JS, Mallampalli RK. Cleavage of signal regulatory protein alpha (SIRPalpha) Enhances inflammatory signaling. J Biol Chem. 2015;290(52):31113-25.

39. Sikic BI, Lakhani N, Patnaik A, Shah SA, Chandana SR, Rasco D, et al. Firstin-human, first-in-class phase I trial of the anti-CD47 antibody Hu5F9-G4 in patients with advanced cancers. J Clin Oncol. 2019;37(12):946-53.

40. Murata Y, Saito Y, Kotani T, Matozaki T. CD47-signal regulatory protein alpha signaling system and its application to cancer immunotherapy. Cancer Sci. 2018;109(8):2349-57.

41. Ring NG, Herndler-Brandstetter D, Weiskopf K, Shan L, Volkmer JP, George BM, et al. Anti-SIRPalpha antibody immunotherapy enhances neutrophil and macrophage antitumor activity. Proc Natl Acad Sci USA. 2017;114(49):E10578-85.

42. Takenaka K, Prasolava TK, Wang JC, Mortin-Toth SM, Khalouei S, Gan Ol, et al. Polymorphism in SIRPa modulates engraftment of human hematopoietic stem cells. Nat Immunol. 2007:8(12):1313-23.

43. Dahan R, Sega E, Engelhardt J, Selby M, Korman AJ, Ravetch JV. FcgammaRs modulate the anti-tumor activity of antibodies targeting the PD-1/ PD-L1 axis. Cancer Cell. 2015;28(3):285-95.

44. Arce Vargas F, Furness AJS, Litchfield K, Joshi K, Rosenthal R, Ghorani $E$, et al. Fc effector function contributes to the activity of human antiCTLA-4 antibodies. Cancer Cell. 2018;33(4):649-663 e4.

45. DiLillo DJ, Ravetch JV. Differential Fc-receptor engagement drives an antitumor vaccinal effect. Cell. 2015;161(5):1035-45.

46. Weiskopf K, Ring AM, Ho CC, Volkmer JP, Levin AM, Volkmer AK, et al. Engineered SIRPalpha variants as immunotherapeutic adjuvants to anticancer antibodies. Science. 2013;341(6141):88-91.

47. Pincetic A, Yang J, Deresa I, Ho W-H, Long H, Maslyar D, et al. 34th annual meeting \& pre-conference programs of the society for immunotherapy of cancer (SITC 2019): part 2. J ImmunoTher Cancer. 2019;7(1):283.

48. Pincetic A, Culp P, Rosenthal A, inventors; ALECTOR LLC, assignee. Anti-SIRP-beta1 antibodies and methods of use thereof. WO patent WO 2020/006374 A3. 2020 2019/06/28.

49. Sockolosky JT, Dougan M, Ingram JR, Ho CC, Kauke MJ, Almo SC, et al. Durable antitumor responses to CD47 blockade require adaptive immune stimulation. Proc Natl Acad Sci USA. 2016;113(19):E2646-54.

50. Yanagita T, Murata Y, Tanaka D, Motegi SI, Arai E, Daniwijaya EW, et al. AntiSIRPalpha antibodies as a potential new tool for cancer immunotherapy. JCl Insight. 2017;2(1):e89140.

51. Zhao XW, van Beek EM, Schornagel $K$, Van der Maaden $H$, Van Houdt $M$ Otten MA, et al. CD47-signal regulatory protein-alpha (SIRPalpha) interactions form a barrier for antibody-mediated tumor cell destruction. Proc Natl Acad Sci USA. 2011;108(45):18342-7.

52. Daley JM, Thomay AA, Connolly MD, Reichner JS, Albina JE. Use of Ly6Gspecific monoclonal antibody to deplete neutrophils in mice. J Leukoc Biol. 2008;83(1):64-70.

53. Matsuzaki J, Tsuji T, Chamoto K, Takeshima T, Sendo F, Nishimura T. Successful elimination of memory-type CD8+T cell subsets by the administration of anti-Gr-1 monoclonal antibody in vivo. Cell Immunol. 2003;224(2):98-105

54. Liu X, Liu L, Ren Z, Yang K, Xu H, Luan Y, et al. Dual targeting of innate and adaptive checkpoints on tumor cells limits immune evasion. Cell Rep. 2018:24(8):2101-11.

55. Moynihan KD, Opel CF, Szeto GL, Tzeng A, Zhu EF, Engreitz JM, et al. Eradication of large established tumors in mice by combination immunotherapy that engages innate and adaptive immune responses. Nat Med. 2016;22(12):1402-10.

56. Liu J, Xavy S, Mihardja S, Chen S, Sompalli K, Feng D, et al. Targeting macrophage checkpoint inhibitor SIRPalpha for anticancer therapy. JCI Insight. 2020;5(12):e134728.

\section{Publisher's Note}

Springer Nature remains neutral with regard to jurisdictional claims in published maps and institutional affiliations.

Ready to submit your research? Choose BMC and benefit from:

- fast, convenient online submission

- thorough peer review by experienced researchers in your field

- rapid publication on acceptance

- support for research data, including large and complex data types

- gold Open Access which fosters wider collaboration and increased citations

- maximum visibility for your research: over 100M website views per year

At BMC, research is always in progress.

Learn more biomedcentral.com/submissions 